\title{
Chapter 3 \\ Tailoring of Thermophysical Properties of New TRIP/TWIP Steel Alloys to Optimize Gas Atomization
}

\author{
Iurii Korobeinikov, Humberto Chaves and Olena Volkova
}

\begin{abstract}
This work is dedicated to the optimization of the inert gas atomization process applied for production of steel powders. One aim is the optimization of melt parameters with the target to reduce the particle size of atomized powder. A second aim is focused on the atomization equipment optimization. In order to study thermophysical properties of steel melts the development of a new research units was accomplished: Maximum Bubble Pressure device for measurement of the surface tension and density of liquid steels and alloys, patented vibrating finger viscometer, dedicated to the investigation of low-viscosity fluids under the conditions of high temperatures and high reactivity of the studied media; density measurement cell based on the Archimedean principle for the precise estimation of steel alloys density. Then, the effect of thermophysical properties on the inert gas atomization of high-alloy steels was studied. The effects of alloying with Mn and Ni were studied as well as microalloying with $\mathrm{S}, \mathrm{P}, \mathrm{Se}$ on the surface tension and viscosity of liquid steels. Surface tension and viscosity modification of the alloys led to considerable reduction of the size of inert gas atomized powders. Alloying with $\mathrm{N}$ allowed finding effect on the powder phase structure.
\end{abstract}

\footnotetext{
I. Korobeinikov $(\bowtie) \cdot$ O. Volkova

Institute of Iron and Steel Technology, Technische Universität Bergakademie Freiberg, Freiberg, Germany

e-mail: Iurii.Korobeinikov@iest.tu-freiberg.de

O. Volkova

e-mail: volkova@iest.tu-freiberg.de

H. Chaves

Institute of Mechanics and Fluid Dynamic, Technische Universität Bergakademie Freiberg,

Freiberg, Germany

e-mail: Humberto.Chaves@imfd.tu-freiberg.de
}

H. Biermann and C. G. Aneziris (eds.), Austenitic TRIP/TWIP Steels

and Steel-Zirconia Composites, Springer Series in Materials Science 298,

https://doi.org/10.1007/978-3-030-42603-3_3 


\subsection{Surface Tension and Density of the TRIP/TWIP Steels}

The main target of the research from the very beginning was a development of new steel grades which may be used as a steel matrix of the steel-ceramic composites. The solid state subproject has developed $3 \mathrm{Cr}-\mathrm{Mn}-\mathrm{Ni}$ steels with varying $\mathrm{Ni}$ content: $16 \% \mathrm{Cr} 7 \% \mathrm{Mn} 3 \% \mathrm{Ni}$ (in Table 3.1 and further it refers to 16-7-3), $16 \% \mathrm{Cr} 7 \% \mathrm{Mn} 6 \% \mathrm{Ni}$ (16-7-6) and 16\% Cr7\% Mn9\% Ni (16-7-3). As long as these 3 new TRIP/TWIP-effect steel grades were developed, the thermophysical properties of them in a liquid state had to be investigated (Table 3.1). The primary objective of such investigation is to deliver insights on the surface tension and density of the new alloys, as well as their infiltration into ceramics capabilities.

Institute of Iron and Steel Technologies (IEST) was already equipped with a hightemperature microscope capable for the measurement of wetting angle and surface tension with the classical sessile drop method. It is well known from the literature that Mn-containing steels in a liquid state intensively lose manganese due to evaporation. At the same time, classical sessile drop method features high surface to volume ratio of the investigated liquid sample. Therefore, it was decided to widen the range of applied methods for estimation of thermophysical properties of Mn-containing steels in order to have better validity of obtained results. One of the best alternative methodologies for the estimation of surface tension is a classical maximum bubble pressure technique (MBP). Among its' features are low surface to volume ratio and low sensitivity to the atmosphere around the sample.

Maximum bubble pressure technique is a well-established method for measuring of a surface tension applicable for a variety of liquids ranging from alcohols at room temperatures to liquid metals and oxides at temperatures well above their melting points. A detailed description of the technique can be found in dedicated literature $[1,2]$. The main idea of the method is to measure maximum pressure in the bubble blown in the liquid. The bubble is typically blown through the capillary of a precisely defined inner diameter and with a sharpened tip. Maximum pressure of the gas inside the bubble of a defined diameter indicates the surface tension of the studied liquid. Pressure in the bubble is measured by the sensor attached to the other side of the capillary (to gas supply system). Pressure in the bubble is defined as:

$$
P_{\text {max }}=\frac{2 \sigma}{r_{\text {capillary }}}+\rho * g * h
$$

where $\sigma$ is a surface tension, $r$ is a radius of the bubble (inner radius of the capillary), $\rho$ is a density of the liquid, $g$ is an acceleration of free fall, $h$ is an immersion depth.

The surface tension is then calculated as:

$$
\sigma=0.5 * p_{\max }(h=0) * r_{\text {capillary }}
$$

The density of the studied liquid $(\rho)$ is calculated as a slope of the linear regression $\left(\Delta p_{\max } / \Delta h\right)$ and acceleration of free fall: 


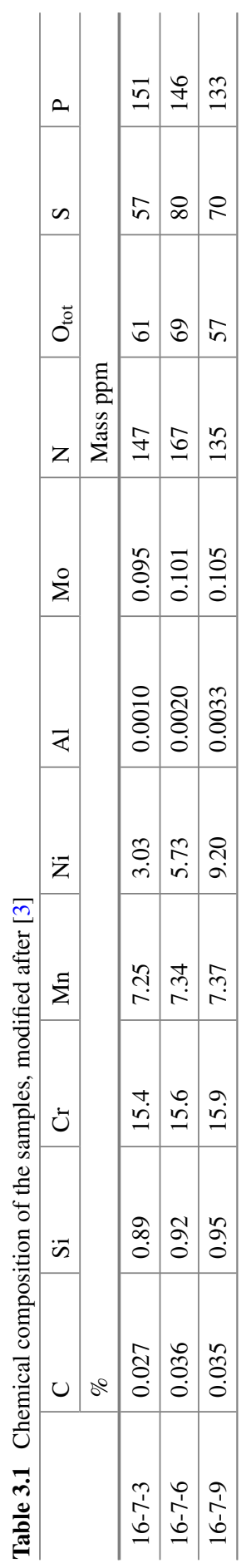




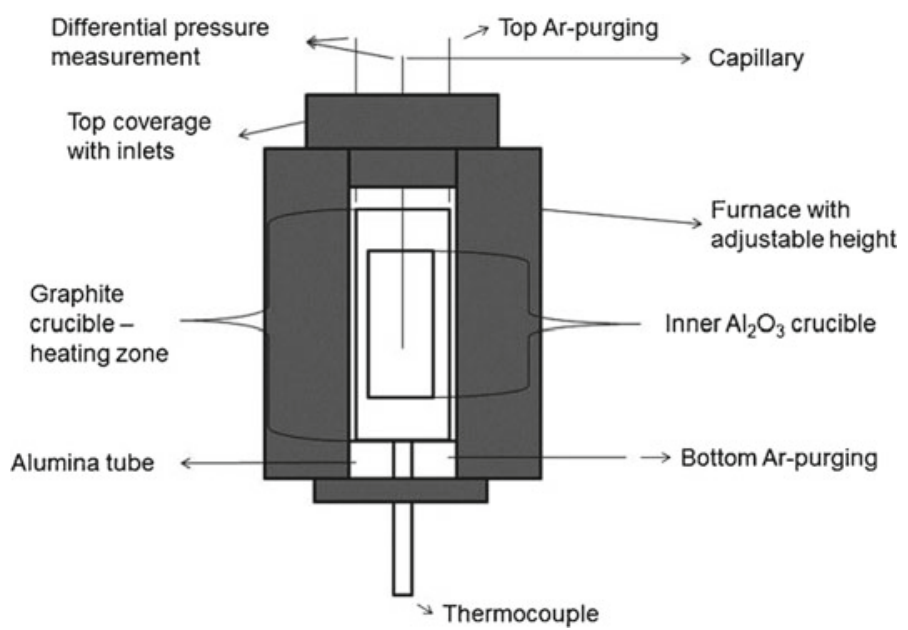

Fig. 3.1 Scheme of the maximum bubble pressure measurement cell $[3,4]$

$$
\rho=\frac{\Delta p_{\max }}{\Delta h * g}
$$

The maximum bubble pressure unit had a scheme as shown in the Fig. 3.1. The sample is molten inside the alumina crucible placed in a graphite heating element. Graphite heating element is inductively heated by the copper coil imbedded in ceramic walls of the furnace. The inner volume of the furnace is continuously flushed with argon 5.0 (99.999\% purity) from the liquid storage tank. Presence of carbon in the heating zone of the furnace ensures the elimination of the oxygen around the sample. Temperature control of the sample is executed via a thermocouple attached to the bottom of the ceramic crucible. Alumina capillary of $1.0 \mathrm{~mm}$ inner diameter is sealed with the zero press rings to the argon supply tube. Immersion of the capillary inside the sample is done by moving of the furnace in a vertical direction. The precision of the capillary position is controlled with $0.005 \mathrm{~mm}$ error with the use of WayCon system. For one temperature point a total of approximately 200 bubbles were measured-ca. 10 bubbles with a step of $1 \mathrm{~mm}$ between 10 and $20 \mathrm{~mm}$ depth along the immersion and subtraction of the capillary.

As a reference, the samples were also investigated with the use of a drop weight method. This method allows deriving the surface tension of the liquid from the weight of the droplet passing through the orifice of known diameter. Principal scheme of the measurement cell is shown on Fig. 3.2. Steel melt is pressed out of the alumina crucible through the $\mathrm{ZrO}_{2}$ capillary by a stamp (piston) and forms a droplet on the orifice of the capillary surrounded by Ar gas (99.999\% purity). As soon as gravity force exceeds the surface tension force, the droplet detaches from the capillary tip. The weight of the droplets is measured with the use of high precision balance. Thus, the (3.4) is used for the estimation of the surface tension of the sample. 


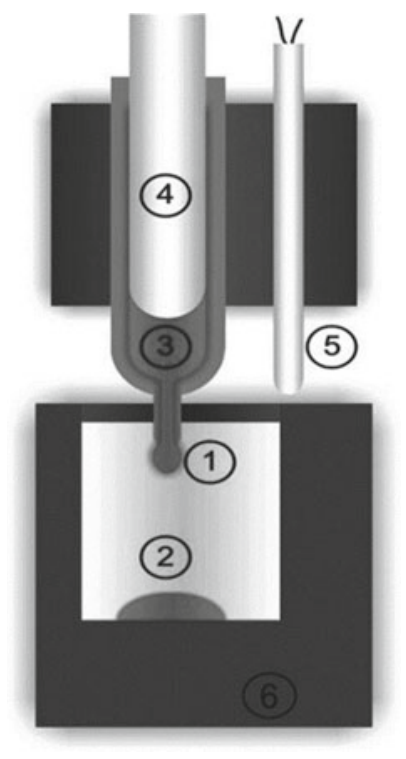

Fig. 3.2 Scheme of the drop weight method for the investigation of surface tension of liquid metals. (1) capillary, (2) crucible, (3) liquid metal bath, (4) stamp, (5) thermocouple, (6) precision balance, modified after [3]

(a)

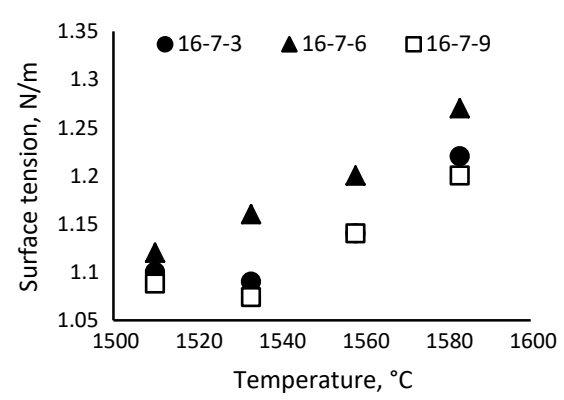

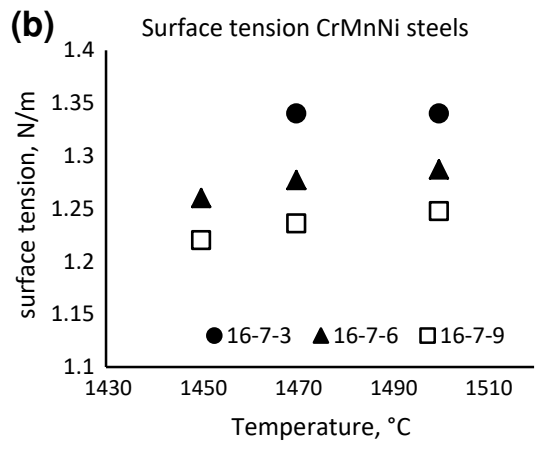

Fig. 3.3 The surface tension of $\mathrm{Cr}-\mathrm{Mn}-\mathrm{Ni}$-steels determined by a the maximum bubble pressure method (MBP) and b drop weight method (DWM), based on [3]

$$
\sigma=\frac{m * g}{2 * \pi * r * \psi}
$$

where $m$ is mass of drop, $g$ is an acceleration of free fall, $r$ is a radius of the drop (radius of the capillary), and $\psi$ is a correction factor.

Experiments showed that the surface tension of the investigated alloys is relatively low-in the range of 1.1-1.3 N/m (Fig. 3.3). Drop weight method gave higher values of surface tension than MBP technique. Another significant fact revealed by this 
Table 3.2 Temperature coefficient of surface tension $\mathrm{d} \sigma / \mathrm{d} T$ for investigated steel types, based on [3]

\begin{tabular}{l|l|l}
\hline & MBP $\left(\mathrm{Nm}^{-1} \mathrm{~K}^{-1}\right)$ & $\mathrm{DWM}\left(\mathrm{Nm}^{-1} \mathrm{~K}^{-1}\right)$ \\
\hline $16-7-3$ & $+1.7 \times 10^{-3}$ & $+7.0 \times 10^{-5}$ \\
\hline $16-7-6$ & $+2.0 \times 10^{-3}$ & $+5.1 \times 10^{-4}$ \\
\hline $16-7-9$ & $+1.7 \times 10^{-3}$ & $+4.2 \times 10^{-4}$ \\
\hline
\end{tabular}

study was that the surface tension of these alloys rose with the temperature increase (Table 3.2). Measurement with the MBP technique also delivered the first data on the density of the new TRIP/TWIP alloys (Fig. 3.4). Besides that, the wettability of samples on the $\mathrm{ZrO}_{2}$ ceramics was investigated (Fig. 3.5).

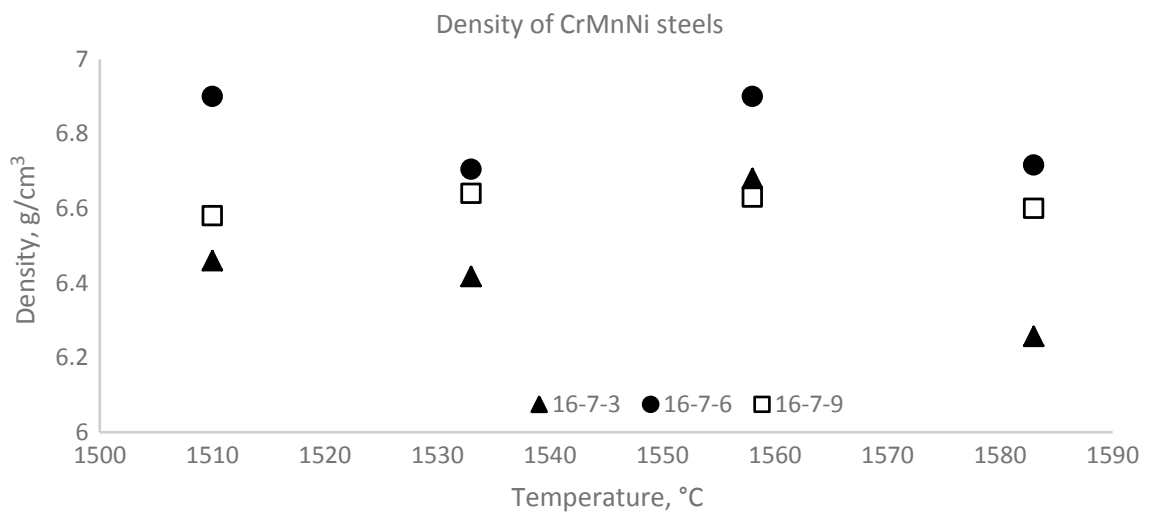

Fig. 3.4 Density of selected Cr-Mn-Ni-steels determined by the maximum bubble pressure method (MBP), based on [3]

Fig. 3.5 Wettability of investigated steel grades on $\mathrm{ZrO}_{2}$ under $\mathrm{Ar} 5.0$ atmosphere $(<2$ mass ppm $\left.\mathrm{O}_{2}\right), 1550^{\circ} \mathrm{C}$; based on [3]

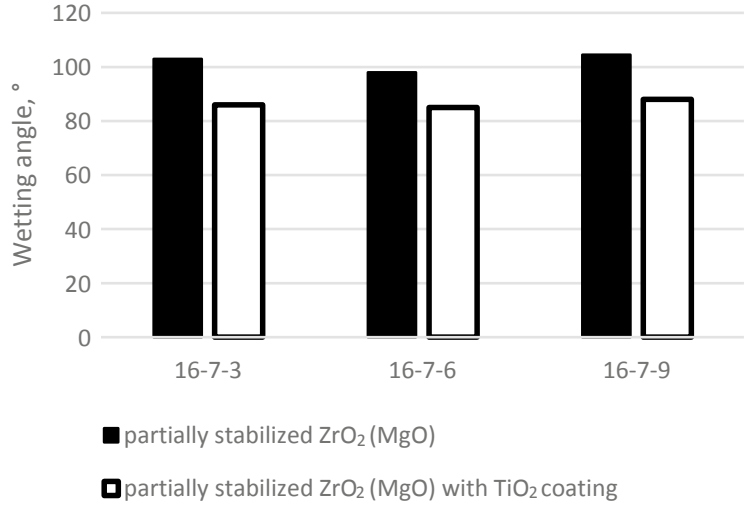


Also, maximum bubble pressure unit was tested on metallurgical slags with the excellent results what showed a capability to their measure surface tension and density [5]. In order to withstand interaction with the slag, the measurement cell was modified - the capillary and crucible were made of molybdenum.

\subsection{Control of Atomization by the Thermophysical Properties of the Atomized Media}

The next research focus was targeted towards investigations of various alloying options of the TRIP/TWIP steels 16-7-3, 16-7-6, and 16-7-9. Besides that, the MBP measurement cell was updated with new capillaries. Preliminary tests showed that $\mathrm{ZrO}_{2}$ ceramic is more corrosion-resistant at high temperatures. Particular interest to this issue was paid due to substantial contents of $\mathrm{Mn}$ in these steel alloys.

New yttria-partially stabilized $\mathrm{ZrO}_{2}$ capillaries were applied for the measurement of surface tension and density of the TRIP/TWIP alloys together with the reference steel grade AISI 304 and electrolytic copper. A surface tension and a density of copper and 304 steel was rather correctly estimated with the applied measurement cell. Remarkably, that a surface tension results of 16-7-3, 16-7-6 and 16-7-9 are in a good agreement with the results obtained in previous work [3] (Fig. 3.6).

This study showed the effect of nickel on the surface tension of liquid steel. Increase of nickel content from 6 to $9 \%$ led to a small decrease of a surface tension

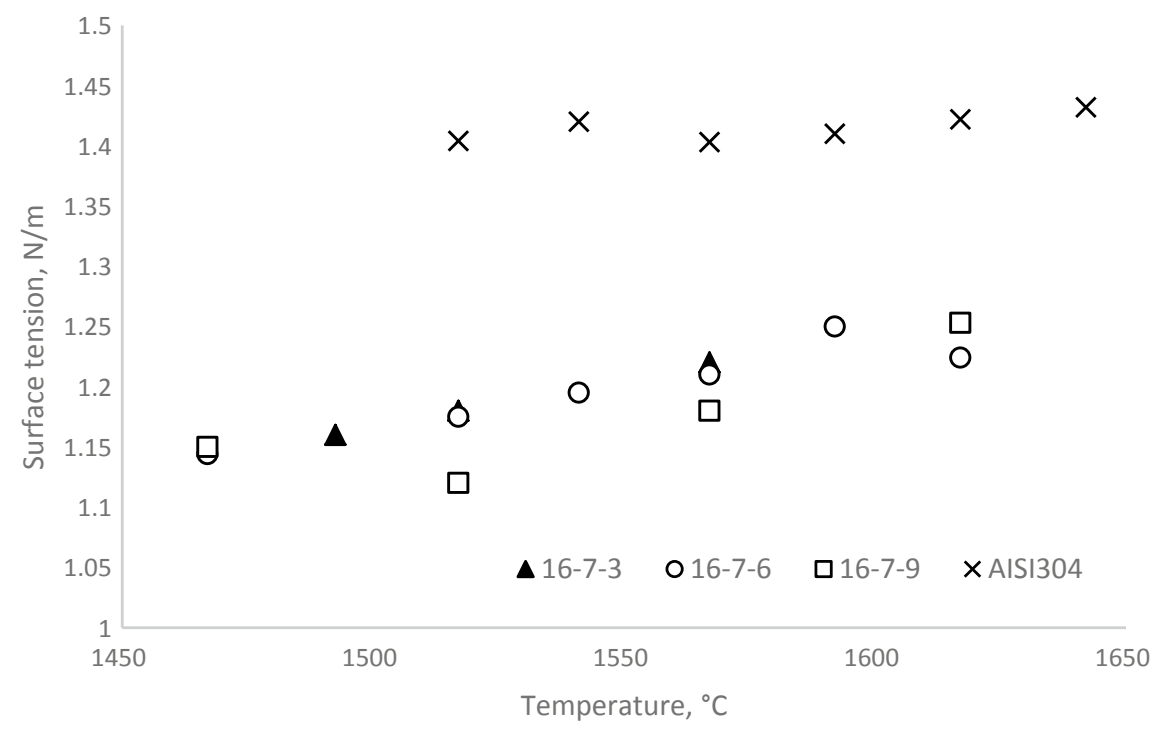

Fig. 3.6 Surface tension of and of TRIP/TWIP alloys compared to AISI 304 (Cr-Ni on the plot) steel, based on [6] 
(Fig. 3.7a). Moreover, the experiments allowed to gain more accurate data on the density of the new alloys (Fig. 3.7b).

Later measurements of the surface tension of TRIP/TWIP steels have shown similar results [7]. It is a notable fact that surface tension values measured with maximum bubble pressure technique are higher than those measured with the sessile drop technique (Fig. 3.8). Simultaneously, a benchmark study was accomplished with the electromagnetic levitation technique (EML) in the DLR facility (Cologne, Germany). It allowed confirming the surface tension of TRIP (16-7-3) steel at temperatures around their liquidus line. However, the features of the EML technique
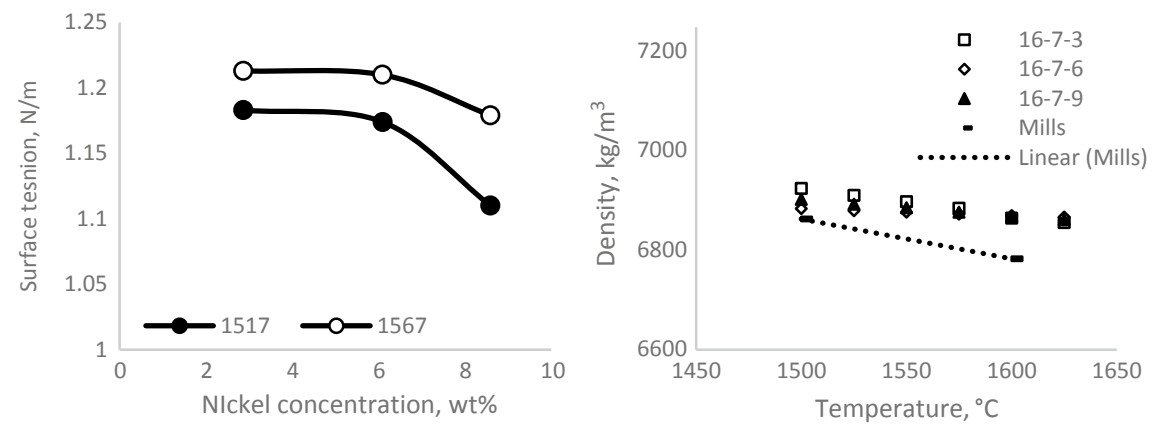

Fig. 3.7 a Effect of nickel on the surface tension of steel. b Density of 16-7-3, 16-7-6 and 16-7-9 steels measured with MBP technique, based on [6]

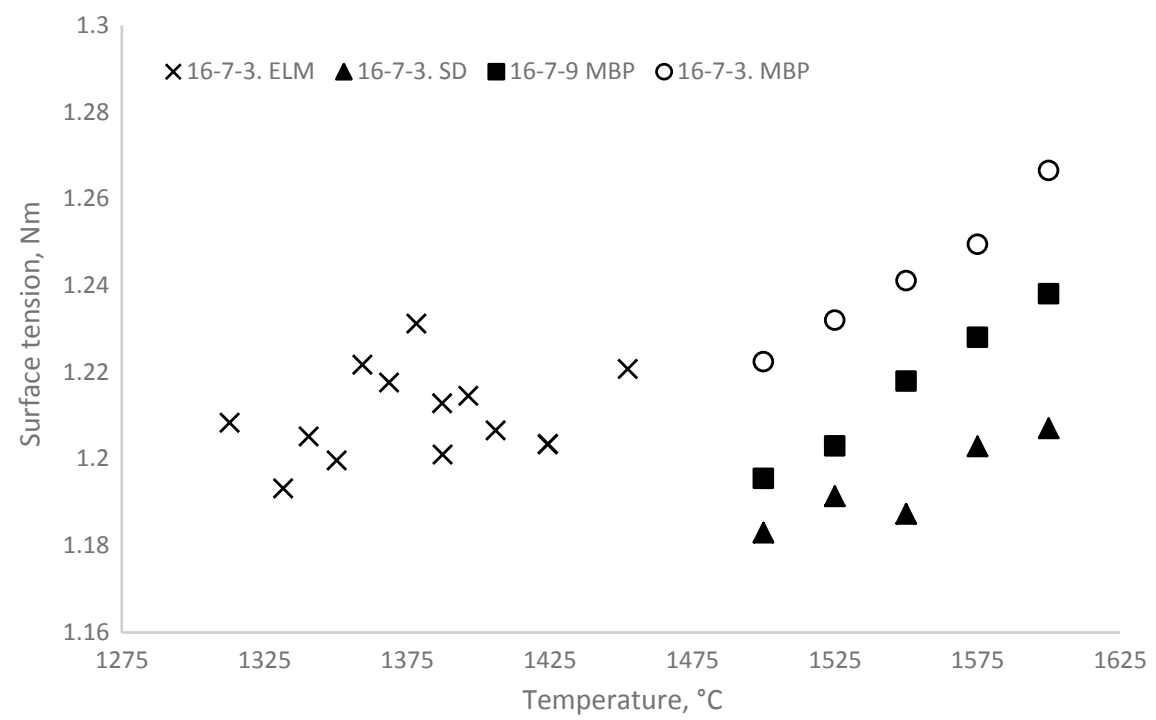

Fig. 3.8 Surface tension of 16-7-3 and 16-7-9 steels measured with maximum bubble pressure (MBP), sessile drop (SD) and electromagnetic levitation (EML) techniques, Modified after [7] 
have led to severe evaporation of manganese. 16-7-3 sample has lost nearly 4 out of $7 \mathrm{wt} \%$ of manganese.

Chemical analysis of the samples before and after the experiments showed the remarkable loses of sulphur. This phenomenon could explain the positive surface tension coefficient.

Besides $\mathrm{Ni}$, the effects of $\mathrm{Mn}, \mathrm{S}, \mathrm{Se}, \mathrm{P}$ on the surface tension of CrNiMn alloys were investigated (Table 3.3) [8]. As can be seen in Fig. 3.9, manganese at low concentrations (until 5\%) significantly reduces the surface tension of the $\mathrm{CrMnNi}$ alloy. Further growth of Mn concentration led to a minor surface tension reduction. Furthermore, the effect of Mn concentration on surface tension diminished with temperature increase.

Alloying with up to $0.22 \%$ phosphorus (Table 3.4 ) did not reveal a clear trend of the effect on surface tension. The surface tension of alloy 16-7-6 slightly rose when phosphor content increased from 0.02 to $0.05 \%$ and further remained stable (Fig. 3.10). At higher temperature $\left(1600{ }^{\circ} \mathrm{C}\right)$ the surface tension of an investigated alloy deviated on $\pm 0.03 \mathrm{~N} / \mathrm{m}$ around $1.21 \mathrm{~N} / \mathrm{m}$.

Among other surface-active elements, selenium is known for its strong effect on the surface tension of liquid iron $[9,10]$. Therefore, a series of Se-microalloyed steels on base of 16-7-6 composition was prepared on VIM-12 unit (Table 3.5). Same as in case of $\mathrm{P}, \mathrm{Mn}$, and $\mathrm{Ni}$, the surface tension of the alloys was measured with the MBP technique. The results of experiments, presented in Fig. 3.12, showed that even a minimum amount of Se $(0.009 \%)$ led to significantly lower ST values than steel alloyed with a comparable amount of sulphur (Fig. 3.11).

\subsubsection{Investigation of the Effect of Surface Tension on Inert Gas Atomization}

Inert gas atomization is one of the variants of a metal powder production. Its main advantages are the sphericity, surface cleanness and controlled chemical composition of the final powder. Among disadvantages are relative complexity of the equipment and high cost of the obtained metal powders. Currently, inert gas atomization technology is the primary source of high-quality powders for the emerging metal $3 \mathrm{~d}$ printing industry. The principle of the gas atomization is based on the disintegration of the liquid metal stream by the gas jet/jets which is well described in the literature $[11,12]$. In the present project the inert gas atomization unit VIGA-1B (ALD-Vacuum Technologies) was used. Principal scheme of the atomizer is given in Fig. 3.13. Sample of metal is inductively heated and melted in a 1 litre tundish located in the upper chamber of the atomizer. Upper chamber can provide vacuum, argon or nitrogen atmosphere. When the liquid is heated to a target temperature, the stopper rod is lifted and metal can flow thru a zirconia nozzle out of the tundish. A stream of metal meets super-sonic close-coupled confined gas jet, streaming out of the steel ring nozzle. Sprayed liquid droplets rapidly solidify while falling into the bottom of the 


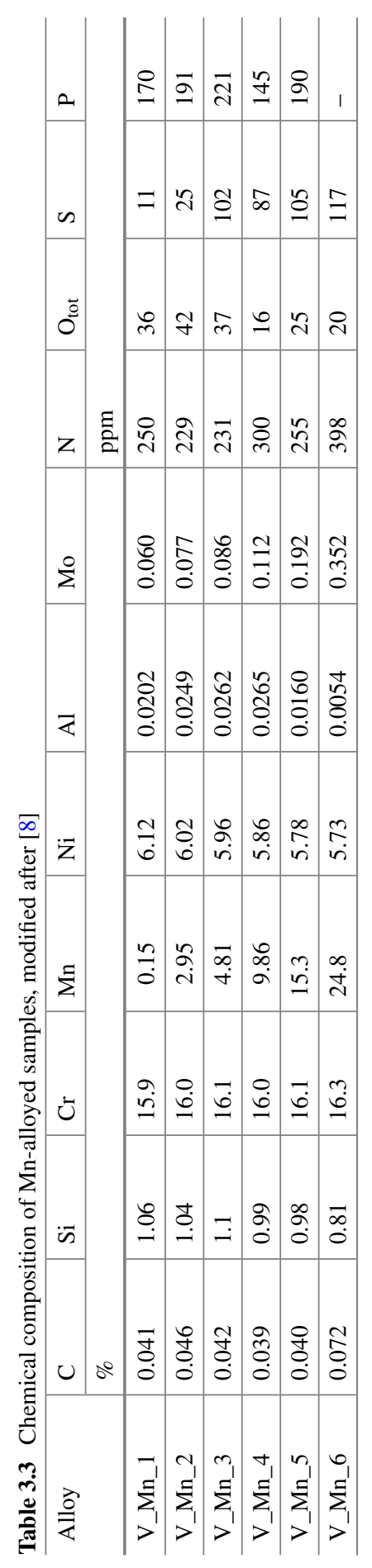




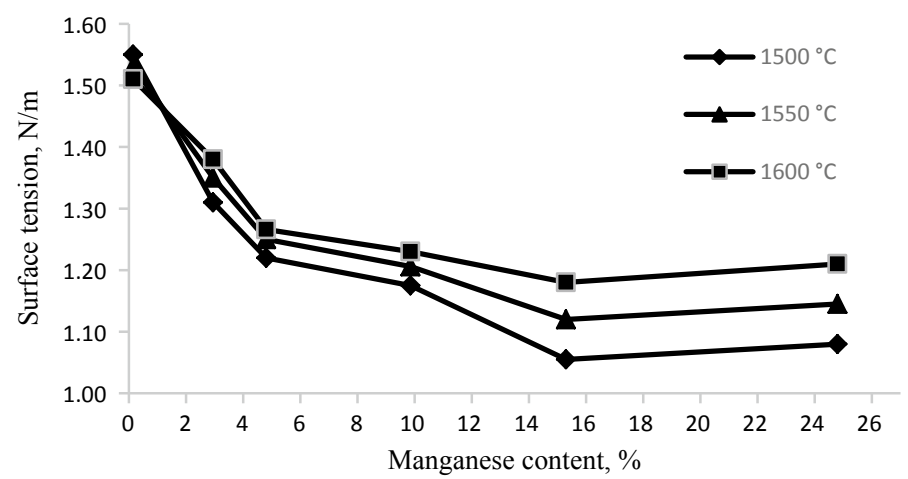

Fig. 3.9 Surface tension of $\mathrm{CrMnNi}$ alloy as a function of Mn content and temperature measured with MBP technique, modified after [8]

atomization vessel. After cooling of the unit, a fine powder is collected from the powder can (trap).

For the atomization of metals argon gas was used in VIGA-1B. Gas was supplied from the liquid storage tank and was re-gasified before injection into the ring nozzle. Gas pressure was 26 bar. In all the experiments the gas flow rate was kept constant and was equal to the technical maximum for the atomization unit.

The main target was to investigate the effect of thermophysical properties of the liquid alloys on the inert gas atomization. One of the easiest characteristics for modification of the molten steel is surface tension. To date, a vast amount of literature data is available on the surface-active elements, which can be applied for steel. Sulphur is known for its strong reducing effect on a surface tension of iron and ironbased alloys [10, 15]. Therefore, a series of alloys based on 16-7-9 steel was prepared with variable sulphur content in the range of 114-984 mass ppm S (Table 3.6). The surface tension of the alloyed steels was measured with the application of MBPtechnique. Figure 3.11 shows that surface tension temperature curves lay substantially lower with the growth of sulphur content in the alloy. As a result, the surface tension of the 16-7-9 alloy at the target atomization temperature of $1600{ }^{\circ} \mathrm{C}$ dropped from 1250 to $1050 \mathrm{mN} \mathrm{m}^{-1}$ what was a $16 \%$ reduction.

Further these sulphur-alloyed steels together with 304 steel (which has much higher surface tension due to lower Mn-content) were atomized at a constant gas pressure and mass flow rate. Analysis of the median particle size $\left(d_{50}\right)$ of the obtained powders (Fig. 3.14) showed a clear and strong dependence of $d_{50}$ on the surface tension of the atomized metal.

Thus, sulphur alloying has shown a remarkable effect on the atomization. Sulphur itself is known as one of the least desirable trump element for most of the steel applications. With this regard, it was decided to check the possibility of $d_{50}$ reduction with other surface active elements. As was given above, selenium showed further tremendous reduction of the surface tension of steel alloy with already low surface tension (Figs. 3.14 and 3.15a). 


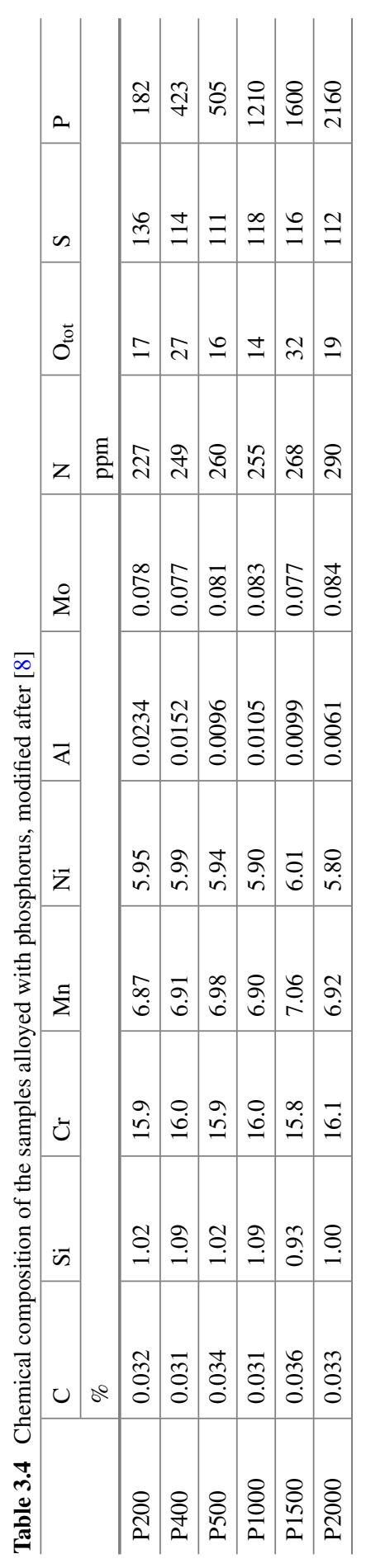




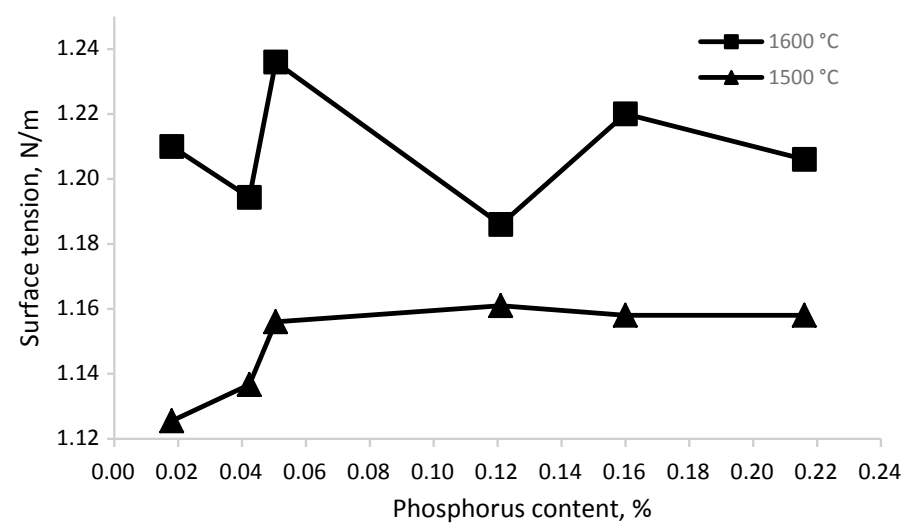

Fig. 3.10 Surface tension of CrMnNi alloy (16-7-6) as a function of phosphorus content measured with MBP technique, modified after [8]

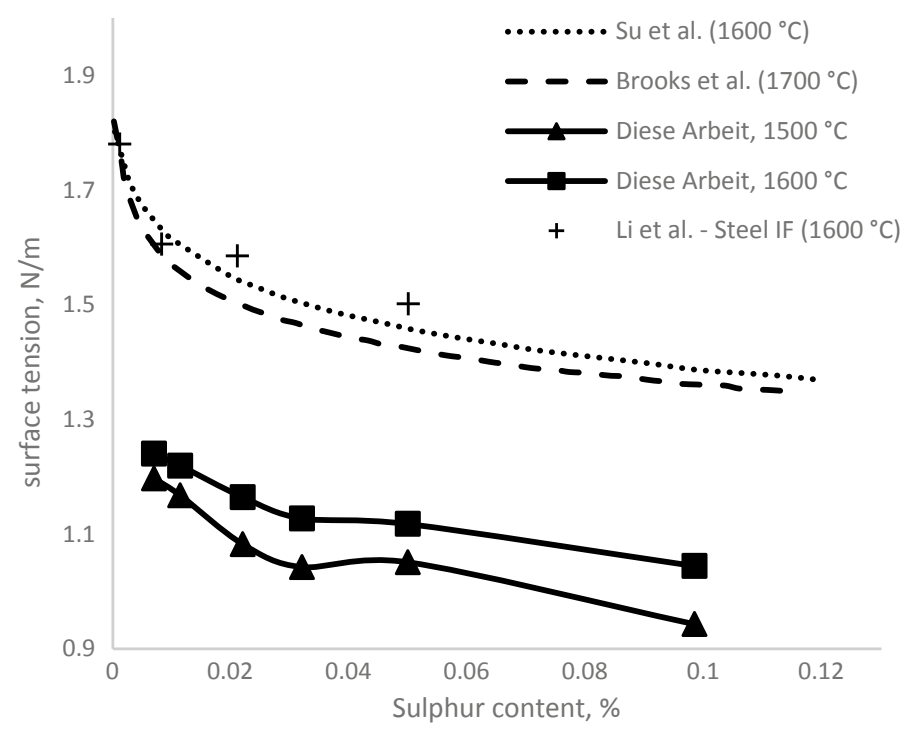

Fig. 3.11 Surface tension of 16-7-9 alloy as a function of sulphur content, modified after [8]

Results of atomizations of Se-alloyed steels showed the same trend on the reduction of median particle size due to a surface tension reduction (Fig. 3.15b). However, data points had higher scatter compared to S-alloyed powders. 


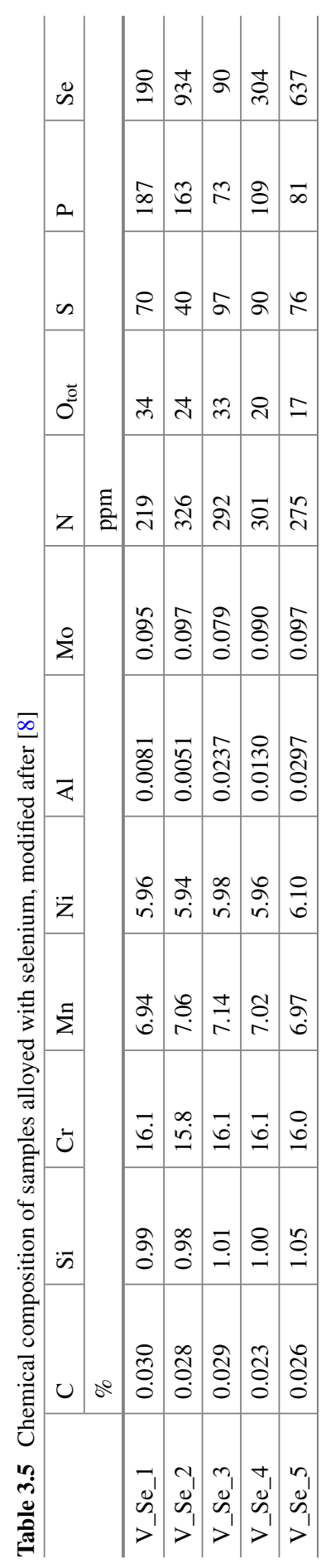




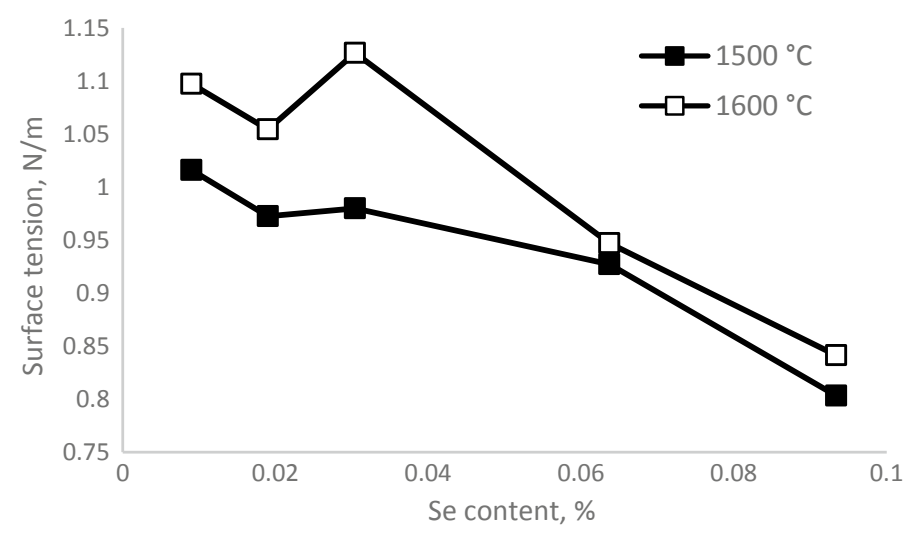

Fig. 3.12 Surface tension of 16-7-6 alloy as a function of selenium content measured with MBP technique, based on [8]
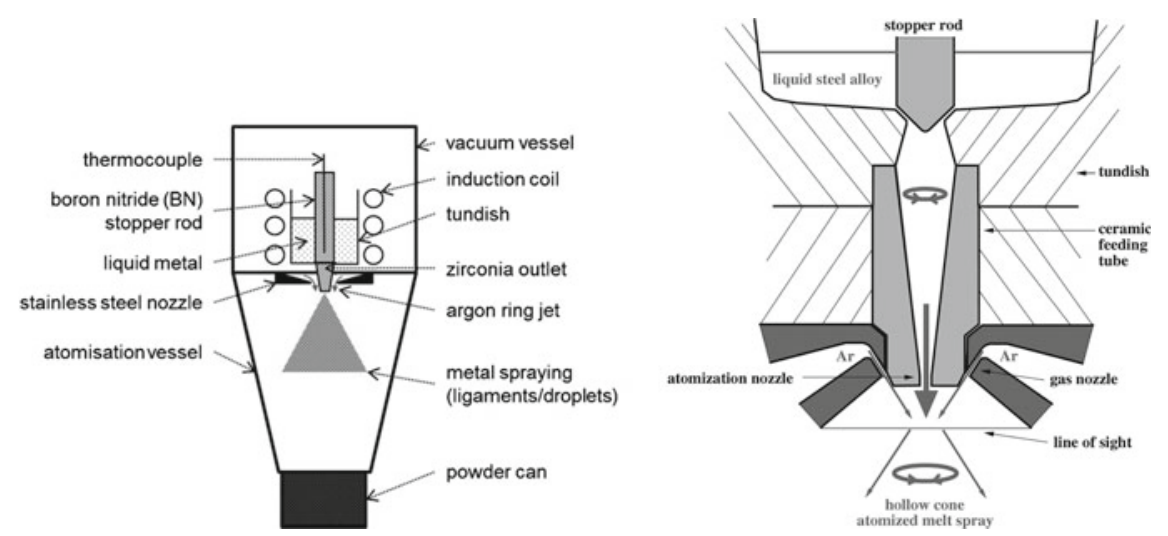

Fig. 3.13 Scheme of the inert gas atomization unit VIGA-1B [13, 14]

\subsubsection{Effect of the Viscosity of Liquid Metal on the Inert Gas Atomization}

It is known from literature, that atomization process is affected by the viscosity of the atomized liquid. In order to investigate this phenomenon, it was necessary to alloy the atomized steels with viscosity modifier. One of the studies accomplished in the framework of CRC 799 has indicated improvement of flowability of the phosphorus-alloyed steel [16]. Moreover, addition of phosphorus did not affect the surface tension - another parameter influencing atomization. Therefore, phosphorus was an ideal alloying element to study the modification of viscosity while other melt parameters being fixed. 


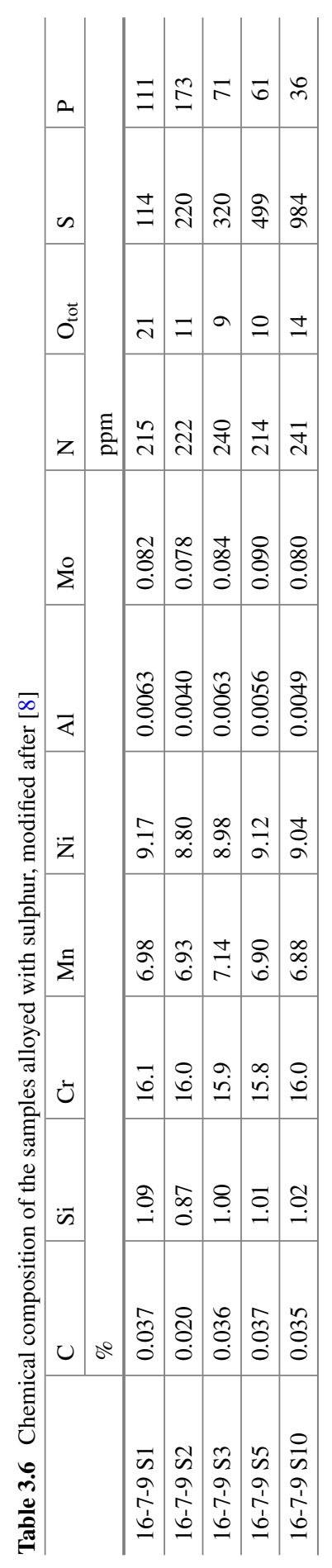




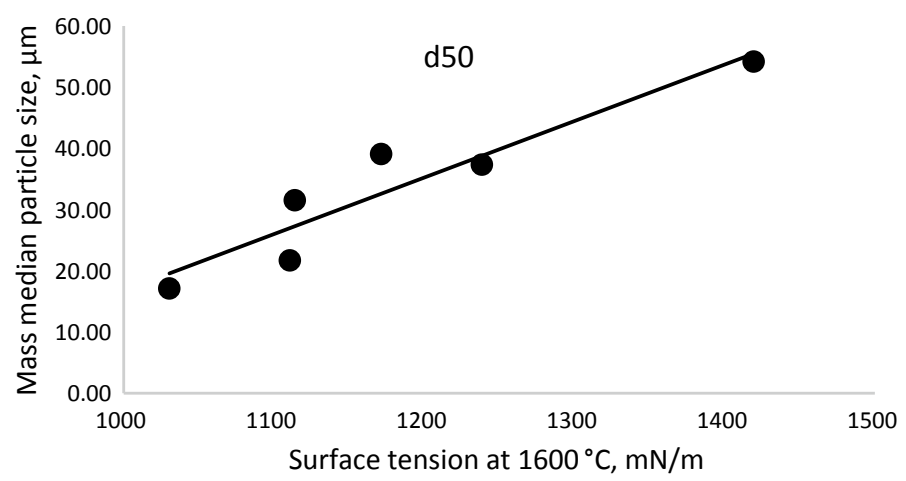

Fig. 3.14 Surface tension of sulphur-alloyed steel (a) and the effect of surface tension on the median particle size of the atomized powder (b), based on [13]
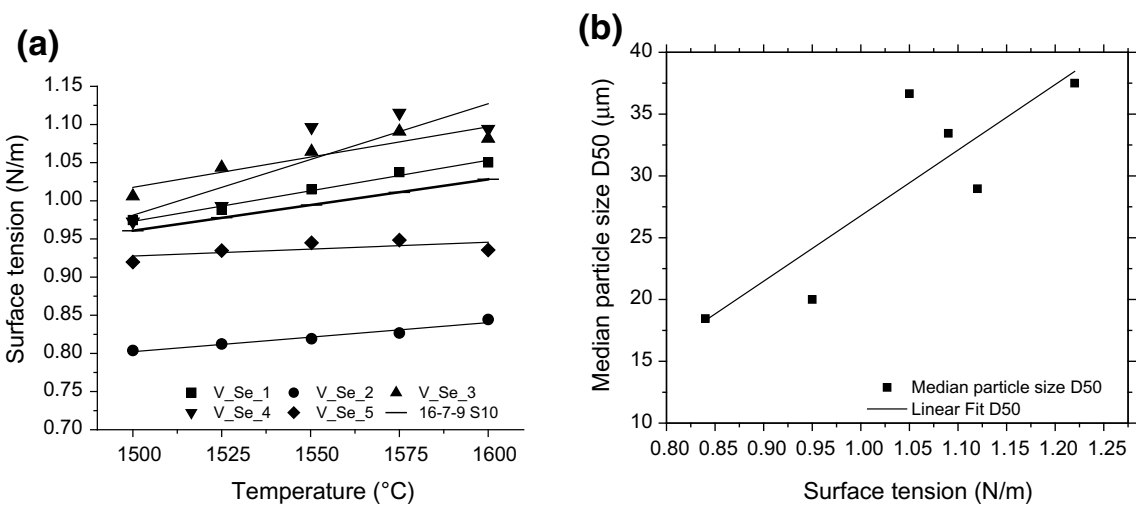

Fig. 3.15 Surface tension reduction by Se-alloying (a), modified after [8], the effect of surface tension on the median particle size $d_{50}(\mathbf{b})$

However, viscosity research required a high-precision viscosity measurement device. High precision was required in order to address even minor changes of such low-viscous liquids as molten $\mathrm{Fe}$-alloys. It is known that steels have a viscosity only slightly higher than water. Beside that, it should be measured at temperatures well above $1450{ }^{\circ} \mathrm{C}$. Additionally, alloys of interest contained $7 \%$ of $\mathrm{Mn}$, what posed additional challenge to selection of materials for measurement instrument. All the above mentioned topics illustrates that the development of the viscosity measurement device was not a trivial task.

An entirely new device capable of low viscosity measurements was developed and patented [17]. Figure 3.16 shows the scheme of the unit and its' measurement head. Vibrating finger viscometer has a unique resonance oscillating head with the amplitude controlled by a laser micrometer. The amplitude is provided by the neodymium magnet excited by a field coil. As soon as a vibrating finger, attached to the oscillating 

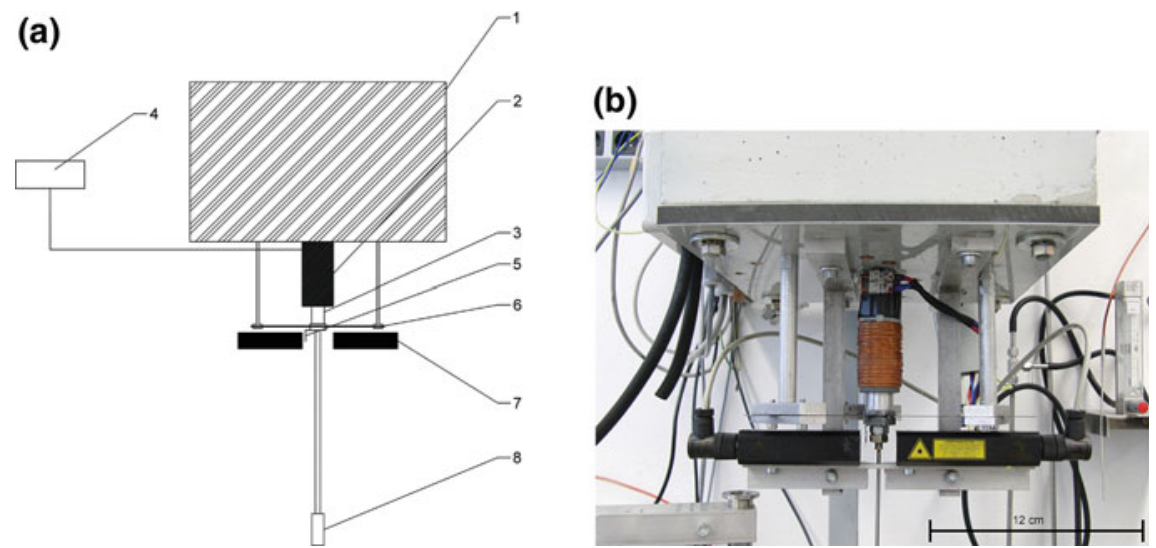

Fig. 3.16 Vibrating finger viscometer: a scheme of the unit, where (1) absorber, (2) field coil, (3) neodymium magnet, (4) microcontroller 12-bit ADC, (5) diaphragm, (6) spring and spring holder, (7) laser micrometer, (8) $\mathrm{BN}-\mathrm{ZrO}_{2}$ finger [18]; $\mathbf{b}$ appearance of the oscillating system [19]

(a)

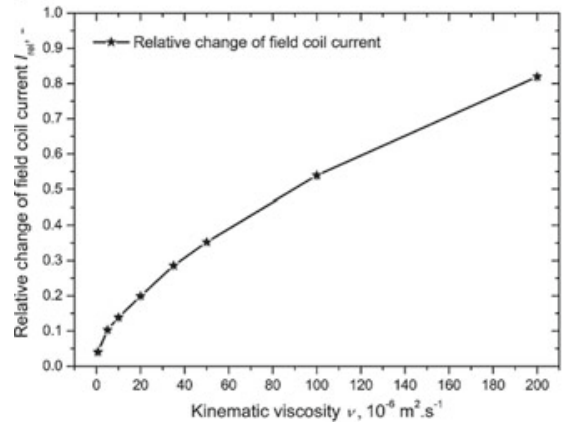

(b)

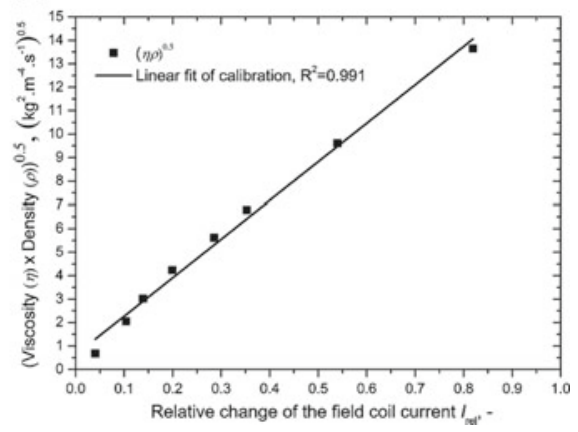

Fig. 3.17 Relative change of the field current as a function of the kinematic viscosity (a) and linear fit of the calibration as a function of the field coil current (b) [19]

head, touches the liquid the current in the field coil rumps-up in order to keep stable amplitude. For the measurement of viscosity, the vibrating finger is immersed into the liquid on $20 \mathrm{~mm}$ depth. The square root of the product of density and viscosity is a function of relative current change in this case:

$$
\sqrt{\eta \rho}=I_{\mathrm{rel}} \cdot b+a
$$

In order to define the viscosity of the measurement a cell is calibrated at room temperature. Calibration is accomplished with the reference liquids of known viscosity (silicon oils) in the range of $0.7-200 \mathrm{mPa}$. As a result, the calibration line is obtained (Fig. 3.17). As can be seen from (3.5), for the estimation of viscosity, the density of the liquid is required. 
An essential aspect of a new cell development was the selection of the material for vibrating finger. The requirements to this material were as follows: easy machinability in order to create complex geometry (screw-thread), high-temperature corrosion resistance to withstand contact with liquid metals and alloying elements, relatively low cost. All these requirements were met in a boron nitride ceramic which was further used as a material for vibrating finger.

The new measurement cell was tested on the metals with vast reference data on their viscosity. The vibrating finger was immersed into liquid gold, silver and tin. Density data on these metals were taken from the previous study [20]. Viscosity values obtained by the newly developed unit are in a very good agreement with the literature values. A viscosity of the liquid gold measured with a vibrating finger viscometer was $\sim 0 \%$ higher than previously reported in literature and decreased from $5.6 \mathrm{mPa}$ at $1100{ }^{\circ} \mathrm{C}(1373 \mathrm{~K})$ to $4.0 \mathrm{mPa}$ s at $1400^{\circ} \mathrm{C}(1673 \mathrm{~K})$. A viscosity of liquid silver was 10-20\% lower than in available literature and decreased from $3.4 \mathrm{mPa}$ at $1000{ }^{\circ} \mathrm{C}(1273 \mathrm{~K})$ to $2.3 \mathrm{mPa} \mathrm{s} 1400{ }^{\circ} \mathrm{C}(1673 \mathrm{~K})$. Liquid tin showed viscosity $20 \%$ lower than reported in literature and reducing from $1.3 \mathrm{mPa}$ s at $600{ }^{\circ} \mathrm{C}(873 \mathrm{~K})$ to $1.1 \mathrm{mPa} s$ at $800{ }^{\circ} \mathrm{C}(1073 \mathrm{~K})$. This research has proven the ability of new viscometer to measure the viscosity of low reactive metals at elevated temperatures.

After a successful measurement of noble metals' viscosity, the next step was to apply the vibrating finger viscometer for the study of the viscosity of the liquid steel alloys. Research cell was used to investigate the effect of nickel content on the viscosity of the $\mathrm{Cr}-\mathrm{Mn}-\mathrm{Ni}$ steel alloys in the temperatures range of $1500-1600{ }^{\circ} \mathrm{C}$ [18]. The measurements were accomplished without severe erosion of vibrating finger surface and geometry changes. As can be seen from Figs. 3.18 and 3.19, the viscosities of CrMnNi steels decrease with temperature and significantly reduce at $20 \%$ of $\mathrm{Ni}$.

In order to investigate the effect of melts' viscosity on the atomization process, a series of phosphorus alloyed steels were prepared (Table 3.5). It is known from literature that phosphorus significantly reduces the viscosity of liquid iron and iron-based alloys [21]. Application of a vibrating finger viscometer has confirmed a decrease of viscosity due to additions of phosphorus. Increase of phosphorus content from 0.022 to $0.2 \%$ led to a reduction of viscosity from $5.0 \mathrm{mPa}$ s to $3.2 \mathrm{mPa}$ s measured at $1600{ }^{\circ} \mathrm{C}$ [8].

Atomization of the phosphorus alloyed steels showed a tremendous effect of viscosity on the size of the powder particles [22]. As it can be seen in Fig. 3.20, there is a linear dependence of the median particle size on the dynamic viscosity at $1600{ }^{\circ} \mathrm{C}$. Decrease of viscosity of $36 \%$ (from 5.0 to $3.2 \mathrm{mPa} \mathrm{s}$ ) led to reduction of $d_{50}$ of $34 \%$ (from 39.5 to $26 \mu \mathrm{m}$ ). 


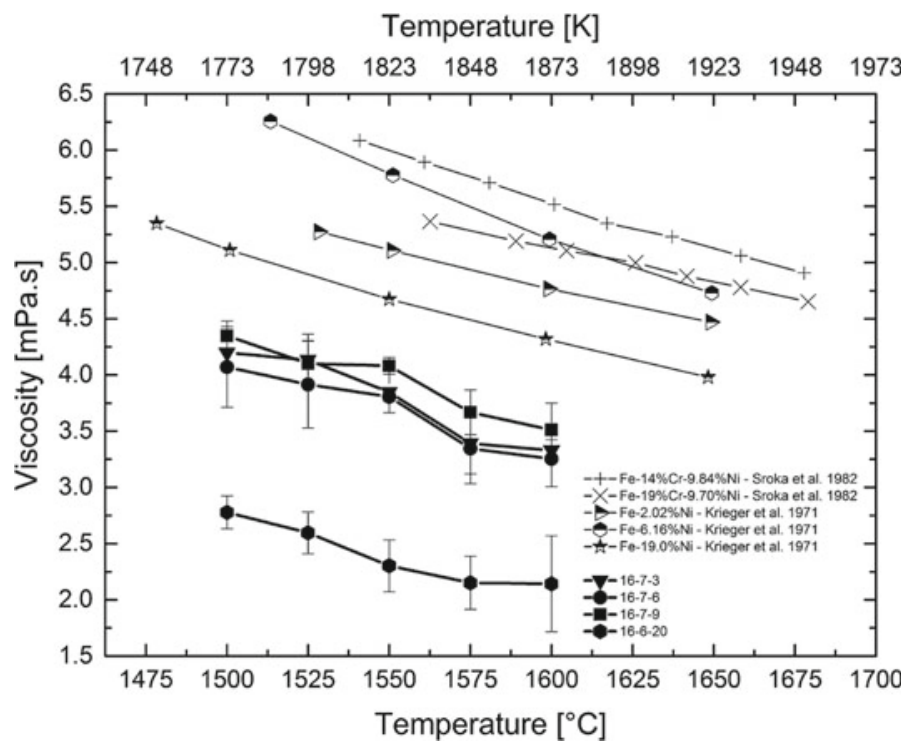

Fig. 3.18 Viscosity of the 16-7-3, 16-7-6, 16-7-9 and 16-7-20 alloys measured with the vibrating finger viscometer compared to previously reported values in the literature [18]

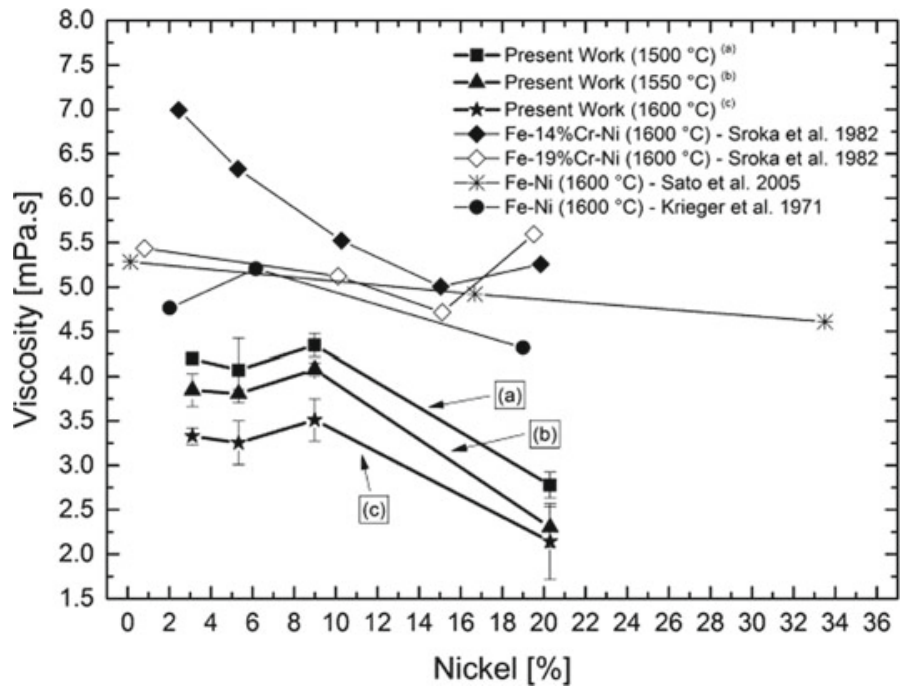

Fig. 3.19 Isothermal viscosity of $\mathrm{Cr}-\mathrm{Mn}-\mathrm{Ni}$ steel with varying nickel content and literature values [18] 
(a)

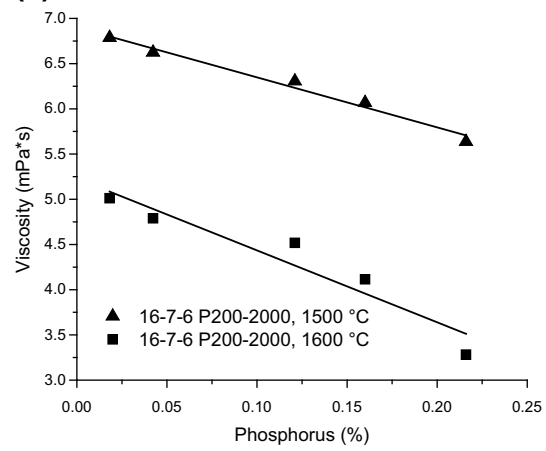

(b)

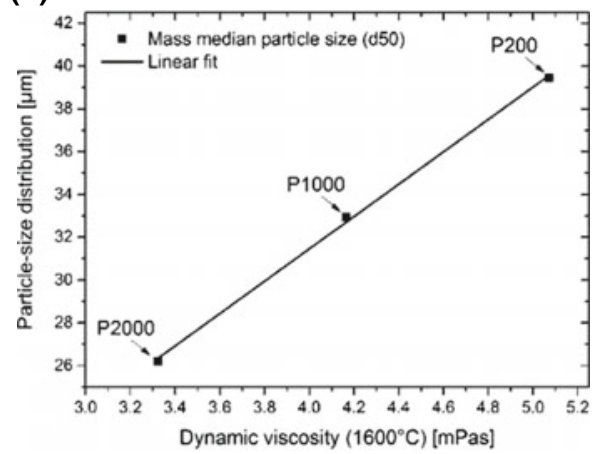

Fig. 3.20 Viscosity of 16-7-6 alloy as a function of phosphorus content measured at 1500 and $1600{ }^{\circ} \mathrm{C}$ based on [8] (a), and effect of viscosity on the median particle size $d_{50}$ of atomized powder based on data from $[8,22](\mathbf{b})$

\subsection{Density of Nitrogen Alloyed Steels}

\subsubsection{Development of Density Measurement Cell}

One of the further targets was to develop a more precise density measurement cell based on the Archimedean principle. Why was the Archimedean principle selected to measure density? There are two features of the density measurement with the Archimedean principle to be selected:

1. High precision. The error of the density values reported in literature for liquid iron is less than $0.5 \%$ [23]

2. Low evaporation of sample and its alloying elements. The sample is usually measured in a ceramic crucible what means low surface to volume ratio.

There are several versions of the direct Archimedean principle methods to measure the density of liquids. In a classical single-sinker method one utilizes one body of a known volume which is immersed in the liquid. The body is suspended on a wire or attached to a thin rod. Presence of the rod has an almost negligible effect on the error of the measurement when single sinker method is applied for measurement of low surface tension liquid, e.g. water or oils. However, when the metals are measured, the effect of a surface tension on the rod has to be accounted for. Surface tension effect depends on the wetting angle between the liquid and the rod material and also on the capillary meniscus direction. These two factors are the primary source of errors for the estimation of liquid metals density with the use of the single-sinker method.

In order to overcome this effect of surface tension, a variety of modifications are proposed in literature [24]. They are based on the idea to use two bodies with different volume but the same rod diameter. When bodies are immersed, the effect of surface tension on their rods is supposed to be the same. However, the weight change 
difference between the two different volumes indicates the density of the measured liquids (3.6). Therefore, the two-sinker method was selected for the measurement of the liquid iron alloys density:

$$
\rho=\frac{\left(W_{1}-W_{0}\right)-\left(w_{1}-w_{0}\right)}{V_{1}-V_{2}}
$$

where $W_{1}$ is the weight of the big sinker immersed in liquid, $W_{0}$ is the weight of big sinker before immersion; $w_{1}$ is the weight of small sinker after immersion in liquid; $w_{0}$ is the weight of small sinker before immersion; $V_{1}$ is a volume of a big sinker, $V_{2}$ is a volume of a small sinker.

An additional measurement cell was added to existing MBP and vibrating finger viscometer facility in such a way that all three measurement units are utilizing the same induction furnace, positioning system and computer hardware. Scheme of the new unit is shown in the Fig. 3.21a. As it can be seen on the scheme, measurement of a density is accomplished via a high-precision balance (1) with the sinker assembly attached to its bottom hook. The assembly consists of molybdenum rod (2) connected to the ceramic rod with the sinker at the end (5). Additional weight (3) can be loaded on the assembly to keep it in vertical direction. The furnace has an extra thermocouple which measures temperature near the melt surface (10). The thermal field in the crucible was checked by immersion of a shielded thermocouple in the molten $\mathrm{Ni}$ and also in solid Mo. It was estimated that temperature in the melt was 8-10 K lower than the one measured by the side thermocouple. Therefore, side thermocouple is used as a sensor of melt temperature during experiments.

The procedure of measurement consists of:

(1) Heating of the sample to a target temperature with the rate of $20-30 \mathrm{~K}$ per minute

(2) 30 min holding time in order to get thermal equilibrium

(3) Measurement of sinker weight on 2-3 mm above the melt

(4) Immersion of sinker into the melt on $1 \mathrm{~mm}$ below the target level

(5) Subtraction of the sinker on the target level and measuring the weight change for $5 \mathrm{~min}$

(6) Repetition of steps 4-5 two more times

(7) Measuring of sinker weight above the melt

(8) Withdrawing of sinker and repetition of steps 3-7 with the second sinker.

Step 4 was added after the preliminary test in liquid lead that showed significant improvement of accuracy due to reducing of a surface tension effect on the ceramic rod (Fig. 3.21b). All the sinkers used in this measurement cell before experiments were immersed into deoxidized water in order to estimate their volume (volume difference of pairs) at room temperature.

Copper, silver, and tin metals were selected for the first application of the measurement cell. The materials were melted in $\mathrm{ZrO}_{2}$ crucibles (yttria-stabilized) and measured with $\mathrm{ZrO}_{2}$ (MgO-stabilised) sinkers. As can be seen in the Fig. 3.26a, density of copper measured by Archimedean principle decreased from $8.06 \mathrm{~g} / \mathrm{cm}^{3}$ at 

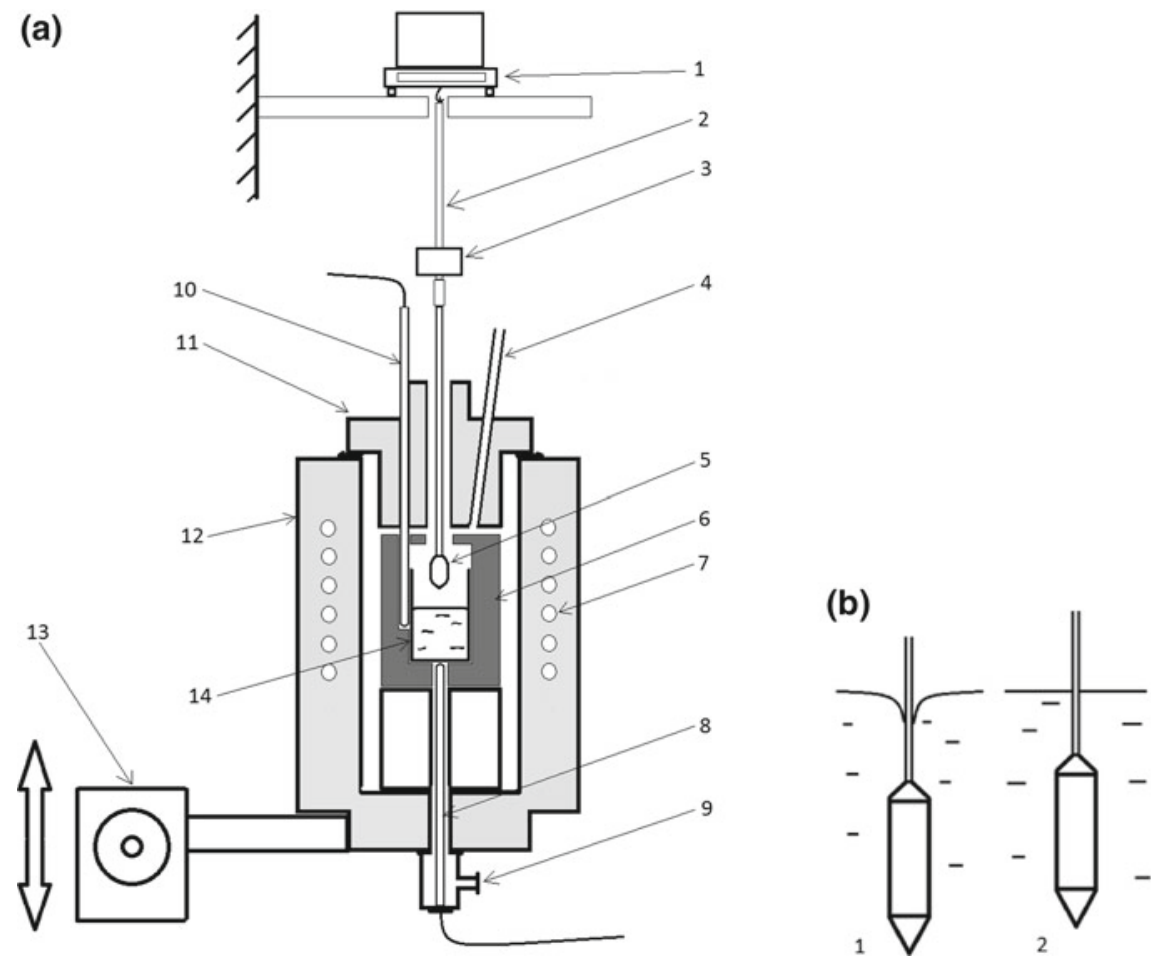

Fig. 3.21 a Density measurement cell. 1 Mettler-Toledo XS105 balance placed on a fixed platform; 2 molybdenum rod; 3 extra load $(\mathrm{Cu}) ; 4$ top input of gas (argon); 5 ceramic sinker; 6 graphite heating crucible; 7 inductor coil; 8 bottom thermocouple (type B); 9 bottom gas input (argon); 10 side thermocouple (tape B); 11 ceramic cover of the reaction chamber; 12 ceramic furnace; 13 electric drive for vertical positioning; 14 graphite crucible [25]. b Shape of the capillary meniscus when sinker is immersed on $1 \mathrm{~mm}$ below the target level (1) and capillary meniscus when sinker is returned to target level (2)

(a)

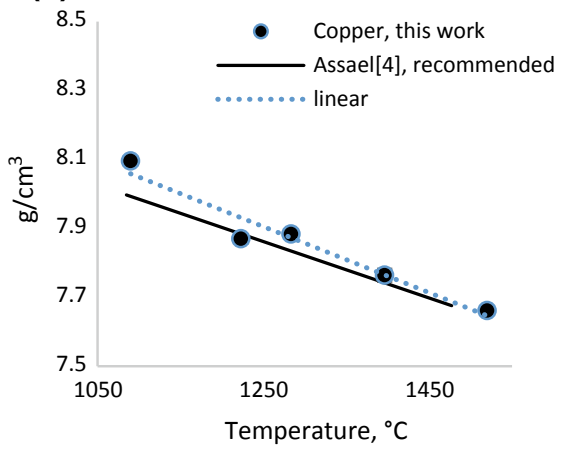

(b)

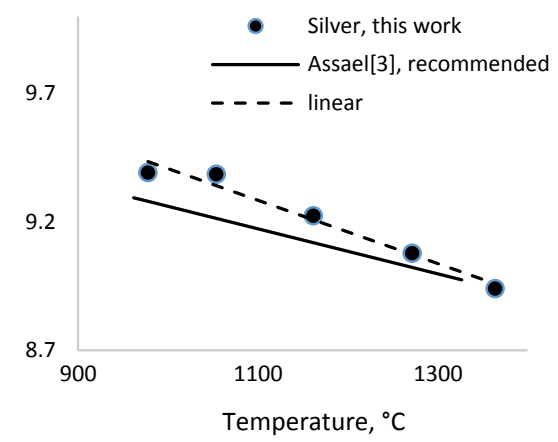

Fig. 3.22 Density of the copper (a) and silver (b) measured with the Archimedean principle with two sinkers method, based on [25] 


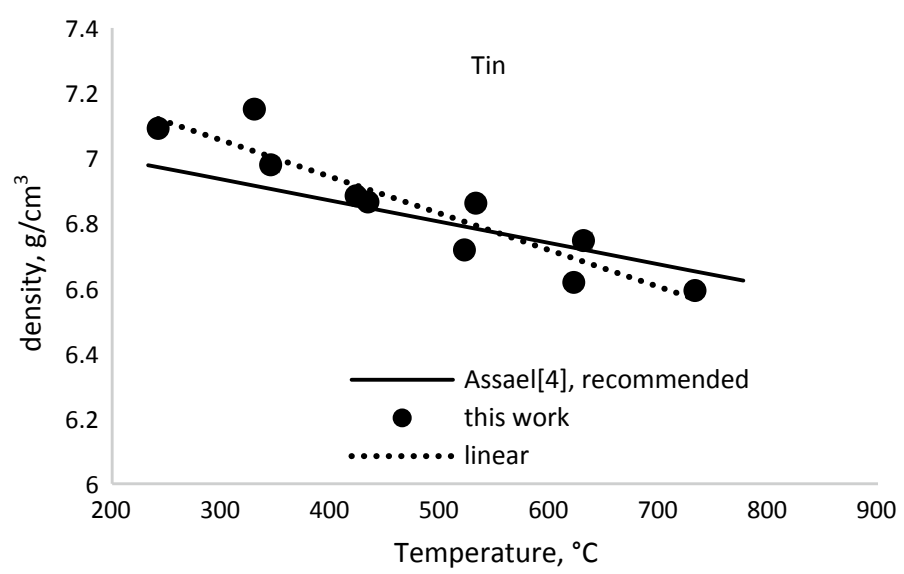

Fig. 3.23 Density of tin measured with the Archimedean principle with two sinkers method, based on [25]

(a)

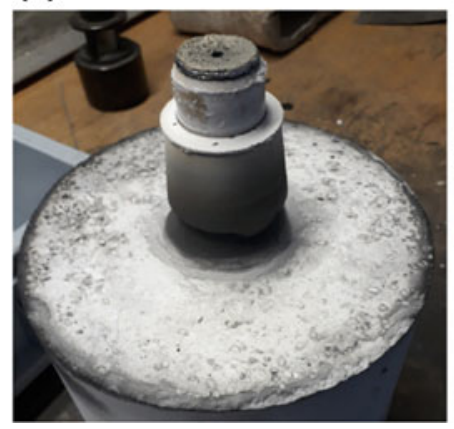

(b)

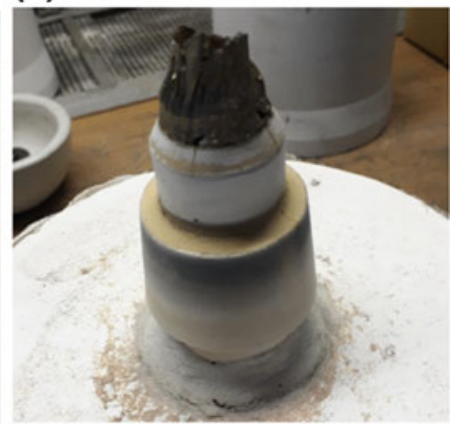

Fig. 3.24 Frozen metal formed on the face of tundish nozzle (crown) after atomization. a Crown is almost absent. b Severe crown formation [28]

$1090{ }^{\circ} \mathrm{C}$ to $7.65 \mathrm{~g} / \mathrm{cm}^{3}$ at $1520^{\circ} \mathrm{C}$. Measured density deviates not more than $1 \%$ from values recommended in literature [26]. Density of silver had slightly higher deviation from recommended values [27] (Fig. 3.22b). Measured density decreased from $9.44 \mathrm{~g} / \mathrm{cm}^{3}$ at $978{ }^{\circ} \mathrm{C}$ to $8.94 \mathrm{~g} / \mathrm{cm}^{3}$ at $1364{ }^{\circ} \mathrm{C}$. As for liquid tin, obtained density (Fig. 3.23) deviated up to $3 \%$ from recommended values [26]. Possible source of the error in the measurement of tin was oxidation of the surface level at temperatures below $700{ }^{\circ} \mathrm{C}$.

In general, the measurement cell showed a relatively good accuracy and is considered for further study of iron-based alloys. It was decided to test a two-sinker method on the investigation of the density of steel alloys $15 \mathrm{NC} 10.15$ and 19NC15.15. 


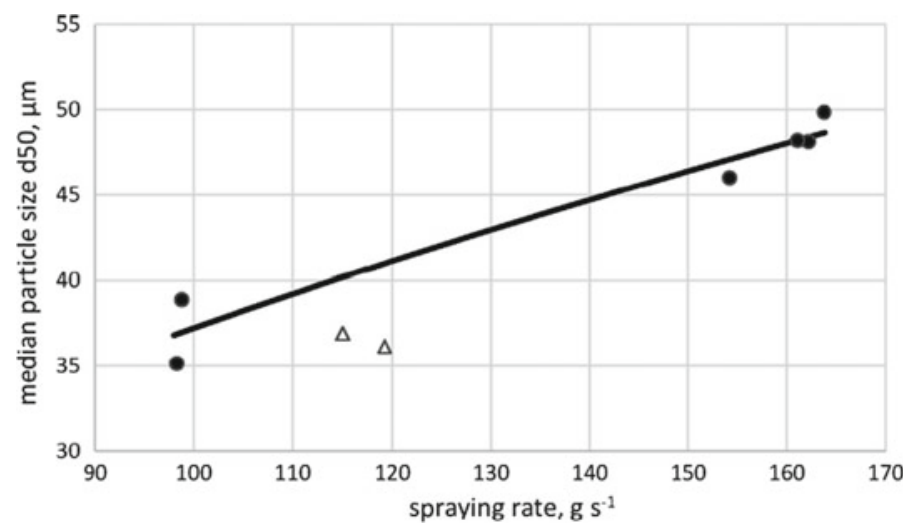

Fig. 3.25 Effect of spraying rate and temperature on the median particle size. Bullet atomized at $1600{ }^{\circ} \mathrm{C}$, Triangle atomized at $1650^{\circ} \mathrm{C}$, square root trend line is built for all experiments at $1600{ }^{\circ} \mathrm{C}$ [28]
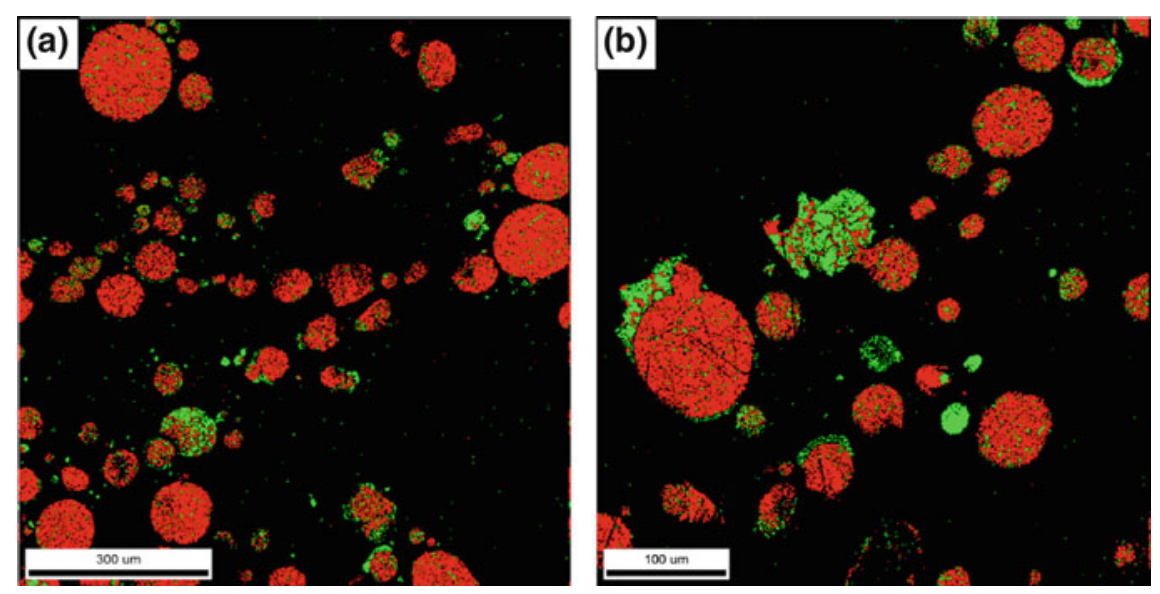

Fig. 3.26 EBSD analysis results for $19 \mathrm{NC} 15.15+\mathrm{V}$ with $2384 \mathrm{ppm} \mathrm{N}$; a overviewand b higher magnification. Red colour represents the austenite phase and green color ferrite phase [28]

\subsubsection{Atomization of Nitrogen Alloyed Steels}

Along the duration of the CRC 799 inew steels $15 \mathrm{NC} 10.15$ and $19 \mathrm{NC} 15.15$ (Table 3.7) were developed. Exceptional tensile strength features of these steels are provided by high nitrogen content. At the same no extensive information on the effect of nitrogen alloying of the melt on the atomization process was found in the literature. Therefore, it was decided to conduct a series of atomization of the new nitrogen-alloyed steels [28]. In this study two parameters were selected as variables-nitrogen content and the temperature of the atomized melt. In order to 


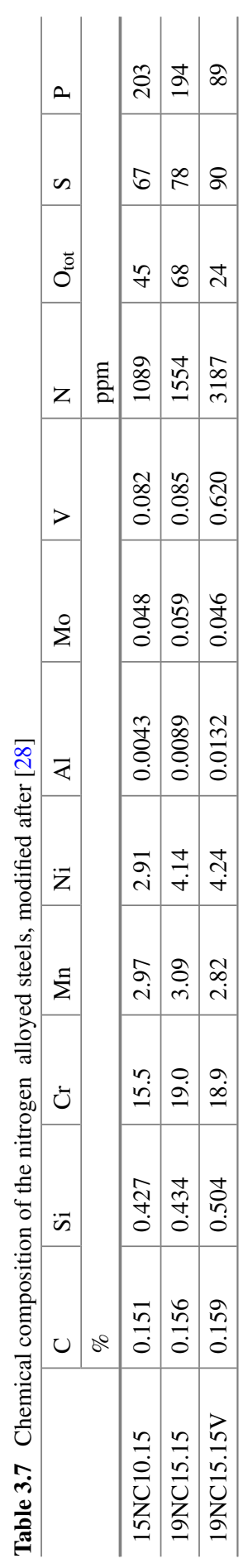


broaden the range of soluble nitrogen content in the steel 19NC15.15 it was alloyed with $0.65 \%$ of vanadium and was named as $19 \mathrm{NC} 15.15+\mathrm{V}$. Atomizations were also accomplished at 1600 and $1650{ }^{\circ} \mathrm{C}$ for steels $15 \mathrm{NC} 10.15$ and $19 \mathrm{NC} 15.15$.

The amount of dissolved nitrogen in the liquid alloy was provided by adjusting argon/nitrogen ratio in the atmosphere in the upper vessel of VIGA-1B. A sampling at $1550{ }^{\circ} \mathrm{C}$ was done before atomization was launched. Unfortunately, not all samplings were successful. However, with the exception of $19 \mathrm{NC} 30.15+\mathrm{V}$ results showed relatively low nitrogen loss directly during atomization-in a range of 80-130 ppm. As for $19 \mathrm{NC} 15.15+\mathrm{V}$, the significant difference between the sample and the powder nitrogen composition could be explained with the sampling procedure described in reference [28].

Series of atomization with variable nitrogen content did not reveal an apparent effect on the median particle size $d_{50}$. At the same time, another factor showed a strong influence on particles size. During the atomizations a frozen crown was formed on the face of the tundish nozzle (Fig. 3.24). The size of this crown was a defining factor for the metal flow rate. During big crown formation, the metal flow rate was reduced what led to lower spraying rate (higher gas/metal ratio). It is known that in industrial practice the gas/metal ratio is the main parameter to control powder size [11]. The results of these experiments were in very good agreement with the typical square root dependence of $d_{50}$ from gas/metal ratio (see Fig. 3.25).

Series of atomization conducted at $1650{ }^{\circ} \mathrm{C}$ showed a significant shift of the value $d_{50}$ below the square root trendline of $1600{ }^{\circ} \mathrm{C}$, thus, illustrating the effect of temperature on refining the size of the particles. These results are in a good agreement with the existing literature on this topic [29].

The samples of two powders with maximum and minimum nitrogen content were analyzed with the use of magnetic saturation method. The results showed that powder with 765 ppm on $N$ had $54 \%$ of ferrite, while sample with 2384 ppm $N$ had only $17 \%$ of ferrite phase. Further analysis with electron backscatter diffraction of SEM confirmed a prevailing of austenite phase in high $N$-containing alloy (Figs. 3.26 and 3.27). Furthermore, particles smaller than $20 \mu \mathrm{m}$ had more ferrite phase than bigger ones $(20<d<200 \mu \mathrm{m})$. This indicated control of both cooling rate and nitrogen upon the austenite stabilization.

\subsection{Analysis of Gas Atomization Process}

This research was dedicated to the production of the inert gas atomized powders with the defined properties for further application in the TRIP-Matrix-Composites. Therefore, a commercial inert gas atomization facility supplied by ALD Vacuum Technologies was applied.

The main targets were:

- To measure and analyse the atomization process

- To study of new nozzles' geometries and systems 

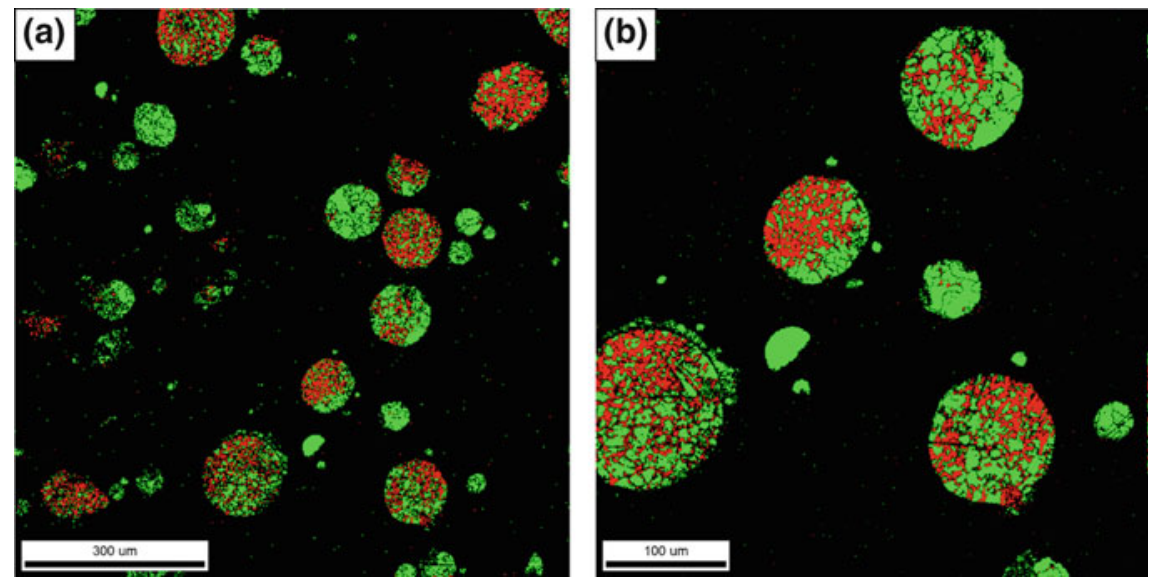

Fig. 3.27 EBSD analysis results for $19 \mathrm{NC} 15.15+\mathrm{V}$ with $765 \mathrm{ppm} \mathrm{N}_{2}$; a overview and b higher magnification. Red color represents the austenite phase and green color ferrite phase [28]

- Targeted influence on the atomization process to produce steel powders of predefined size.

In order to affect the process of atomization it is necessary to accurately study the process of metal spraying. With this regard two special measurement units were developed for the 2-dimensional in situ measurement of temperature and velocity of the fluid particles within the gas atomization process.

\subsubsection{Temperatures of the Particles}

For measurement of the particle surface temperature a 2-color thermographic camera unit was developed [30]. The setup consists of two commercial CCD-cameras with installed dielectric optical filters, optical beam splitter and two lenses as object lenses. The components were selected with the requirements for being operational in the selected filter wavelengths. The maximal spectral emissive power of the studied liquid metal droplets at $1873 \mathrm{~K}$ is expected to be close to a wavelength of $1.5 \mu \mathrm{m}$. CCD camera sensors have their peak sensitivity typically at $0.5 \mu \mathrm{m}$. Their sensitivity at $0.9 \mu \mathrm{m}$ is only a tenth of the maximum value. Therefore, the combined effect is that the recorded signal, i.e. intensity times sensitivity is low. In order to handle this shortcoming longer exposure times are used. This means that not the surface temperature of individual droplets is recorded, but a temporal average of the droplets that cross the area imaged onto each pixel. The cameras have a resolution of 1600 $\times 1200$ pixels of $4.4 \mu \mathrm{m}$ pixel size. Maximum frame rate is $16 \mathrm{fps}$. Images were obtained in an 8-bit greyscale. The optical dielectric bandpass filters have central transmission wavelengths at $\kappa_{1}=(850 \pm 8) \mathrm{nm}$ and $\Lambda_{2}=(900 \pm 8) \mathrm{nm}$. The set-up 
(a)

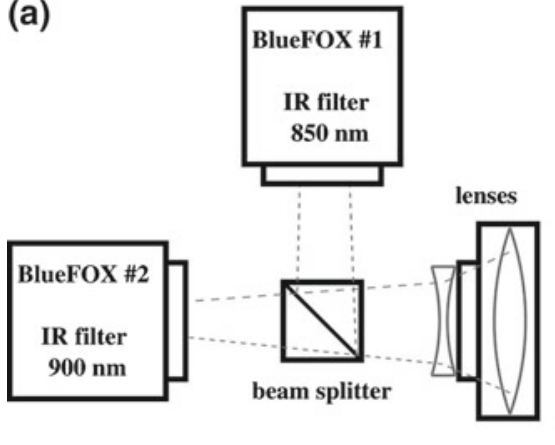

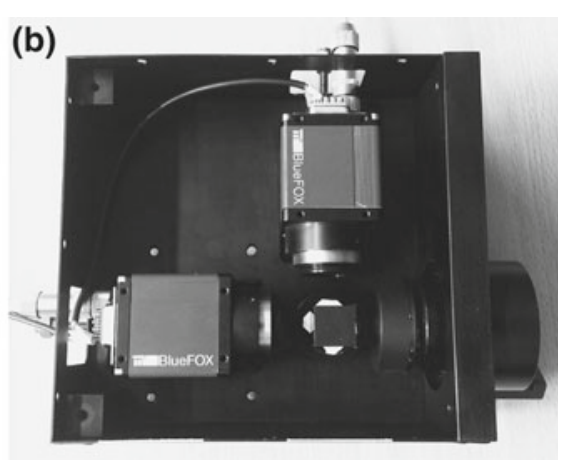

Fig. 3.28 Scheme (a) and picture (b) of the two-color pyrometer [14]

of the two-color pyrometer is shown in Fig. 3.28. The image was focused with the objective "Rollei-HTF Distagon 2.8/35". The images were focused onto the CCD sensors through the beam splitter cube. It splitted the optical path for the two camera sensors.

\subsubsection{Image Processing}

Two-color pyrometer was calibrated using a high-temperature furnace and a sample of silicon carbide in a temperature range of 1273-1873 K. The temperature of the sample was measured with a type $B$ thermocouple assuring $\pm 1.5 \mathrm{~K}$ absolute measurement error. After calibration a particular correction term was obtained.

The newly developed two-color pyrometer was applied for the measurement of the metal stream temperature distribution at atomization in the VIGA-1B unit described previously in Fig. 3.13. The liquid steel (16-7-6 alloy) was heated ca. $200 \mathrm{~K}$ over its liquidus line to $1873 \mathrm{~K}$. When the target temperature was reached, the atomization was launched. Figure 3.29 shows the results of measurements of the time-averaged temperature of the surface of the droplets. Due to the small depth of the field features of the camera, the pictures represent cross-sections of the spraying cone in the first half-second after the metal spraying initiation. The $0 \mathrm{~mm}$ point in the figure refers to the line of sight, which was $40 \mathrm{~mm}$ below the ceramic nozzle face. At $0.0 \mathrm{~s}$ the gas jet was not launched and only the metal stream is visible. At $0.1 \mathrm{~s}$ the disintegration of the metal flow began due to the gas stream. After $0.3 \mathrm{~s}$ the cone of sprayed metal was formed and later remained relatively stable. The primary breakup point was situated about $20 \mathrm{~mm}$ below the line of sight. Below that level a hollow cone of atomized melt with the length of approximately $50 \mathrm{~mm}$ was formed. At lower levels the hollow cone disintegrated on ligaments and droplets. Temperature iso-lines indicate that between 60 and $80 \mathrm{~mm}$ below the line of sight (nozzle metal) material was cooled down to its liquidus line. It corresponds to $100-120 \mathrm{~mm}$ distance from the nozzle face. This 

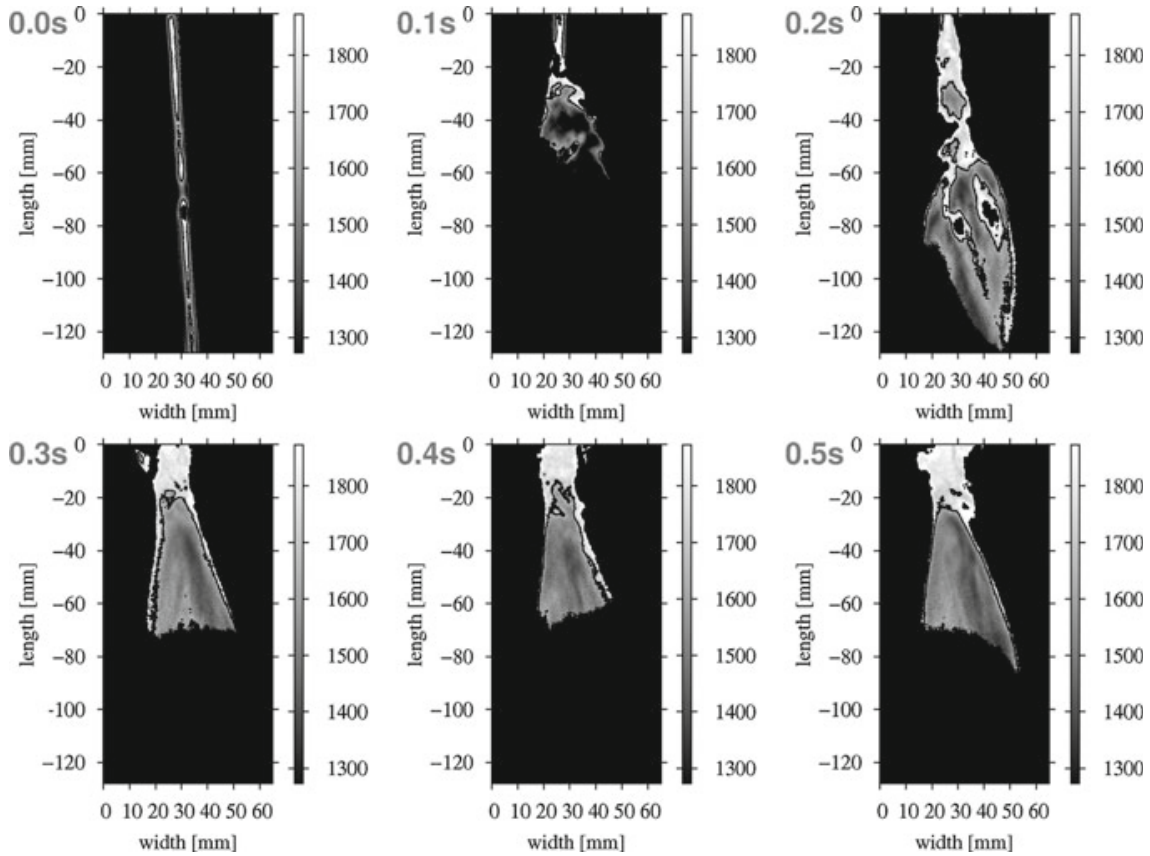

Fig. 3.29 Contour maps of the two-dimensional temperature measurement (in $K$ ) of the melt atomization. The quantity in the upper right corner of each temperature distribution is the image acquisition time $t_{\text {imag. }}$. The black line within the region of the spray denotes the isoline of the liquidus temperature of $1673 \mathrm{~K}$. The purple background means all temperatures are smaller than $1273 \mathrm{~K}$ which are out of the measurement range of the pyrometer, [14]

distance is about 30 times the diameter of the nozzle and is in a good agreement with literature data [31].

\subsubsection{Velocity of the Particles}

For the measurement of the velocity of the particles during metal atomization a special Particle Image Velocimetry (PIV) was applied (Fig. 3.30) [30]. The PIV measurement method is a non-contact optical method for measuring particle velocities in a 2D observation area within a particle flow. This area is defined by a thin light sheet generated by the passage of a laser pulse through a cylindrical lens. Two pulse laser cavities emit two laser pulses with an adjustable temporal separation. The pulse duration is on the order of $5 \mathrm{~ns}$. The scattered light of the illuminated particles is picked up by a double-frame PIV camera arranged perpendicular to the light crosssection. Due to the time interval, the local positions of the particles differ in the double images. Special PIV evaluation software detects these positional differences 
(a)

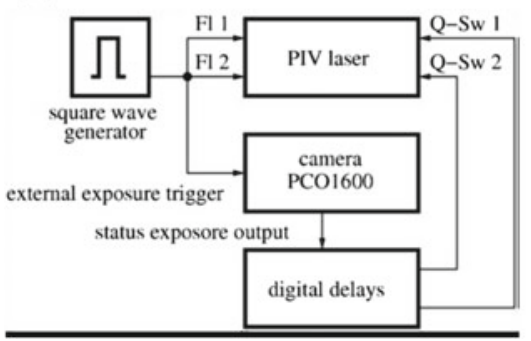

(b)

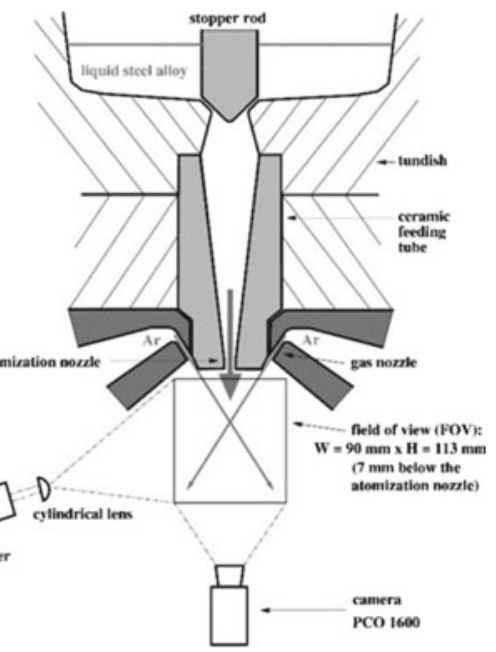

Fig. 3.30 a Block-diagram of the applied measurement apparatus. Square wave generator triggers the measurement with the frequency of $10 \mathrm{~Hz}$. First, the flash-lamps Fl1 and Fl2 are triggered which pump the laser medium with energy. Simultaneously starts the double-images capturing with the PIV camera PCO 1600. In this case, digital delay units send control signals to the Q-Sw 1 and Q-Sw 2 Q-switches, whereby the laser pulses are triggered. The time of the 2nd double image is set in-camera. b Scheme of the atomization area of the VIGA 1B together with the position and size of the observed area (FOV) [30]

using correlation algorithms within the small windows in the image area, which defines a uniform grid structure. From the position difference at the correlation maximum and the time interval, a particle velocity vector is then calculated and assigned to the respective window center point. The result is a $2 \mathrm{D}$ velocity distribution in the observation area. PIV measurements in steel atomizers differ from those in continuous flows due to other boundary conditions.

Usually tracer particles are supplied to the fluids to be examined, which emit scattered radiation when passing the laser light section detected by the camera. Through this controlled particle addition (seeding), the number density of the determined velocity vectors can be significantly increased that aim to measure the flow velocity of the gas. In the present case of steel atomization, the aim is to truly measure the velocity of ligaments and droplets that constitute the particles. The use of a narrow band filter, whose wavelength coincides with that of the PIV laser, effectively blocks the thermal radiation of the melt.

Due to its large particle sizes, the melt in the vicinity of the ceramic nozzle scatters light strongly which leads to over-exposure of adjacent pixels on the camera sensor (blooming effect) and images with overexposed areas. Therefore, the correlation evaluation of the double images gives the wrong velocity data in this region.

Based on numerical simulations [32], it is known that gas velocities in the range of $400-500 \mathrm{~m} / \mathrm{s}$ occur near the atomizer nozzle. The particle velocities in the axial range were calculated to be up to $250 \mathrm{~m} / \mathrm{s}$. The measurement of such high speeds 
requires a correspondingly small time interval between the double pulses of the laser in the order of 2-3 $\mu \mathrm{s}$. The entire measuring system must be triggered exactly in time in order to minimize the measuring error component of the time interval.

Measurements of the particle velocities were conducted for atomization of two steels: X5CrNi18-10 and X3CrNiMo13-4 in VIGA 1B unit. Both steel samples were atomized at the same conditions. Atomization was initiated at ca. $200 \mathrm{~K}$ superheating above the liquidus line at $1600{ }^{\circ} \mathrm{C}$. Evolution in time of the measured particles velocities in the first $0.5 \mathrm{~s}$ after atomization launch is seen in the Figs. 3.31 and 3.32. The plots show a section through atomization cone. It can be seen that after $60 \mathrm{~mm}$ below the ceramic nozzle the metal stream breaks up and forms a hollow cone confirming the results published in [14]. The high speeds in the upper third of the observation window are due to the blooming effect. In the area of the interaction of the melt and atomizing gas, the measured particle velocities range between 120 and $210 \mathrm{~m} / \mathrm{s}$. The white dashed line indicates the area where the solidification temperatures are reached. The particle velocities of both melts in the solidification area are approximately $120 \mathrm{~m} / \mathrm{s}$. Obtained velocities are in a good quantitative agreement with numerically determined data, e.g. as [33]. Comparison of the averaged particles' velocities of two steels revealed that in case of X3CrNiMo13-4 the velocities were smaller than for X5CrNi18-10.

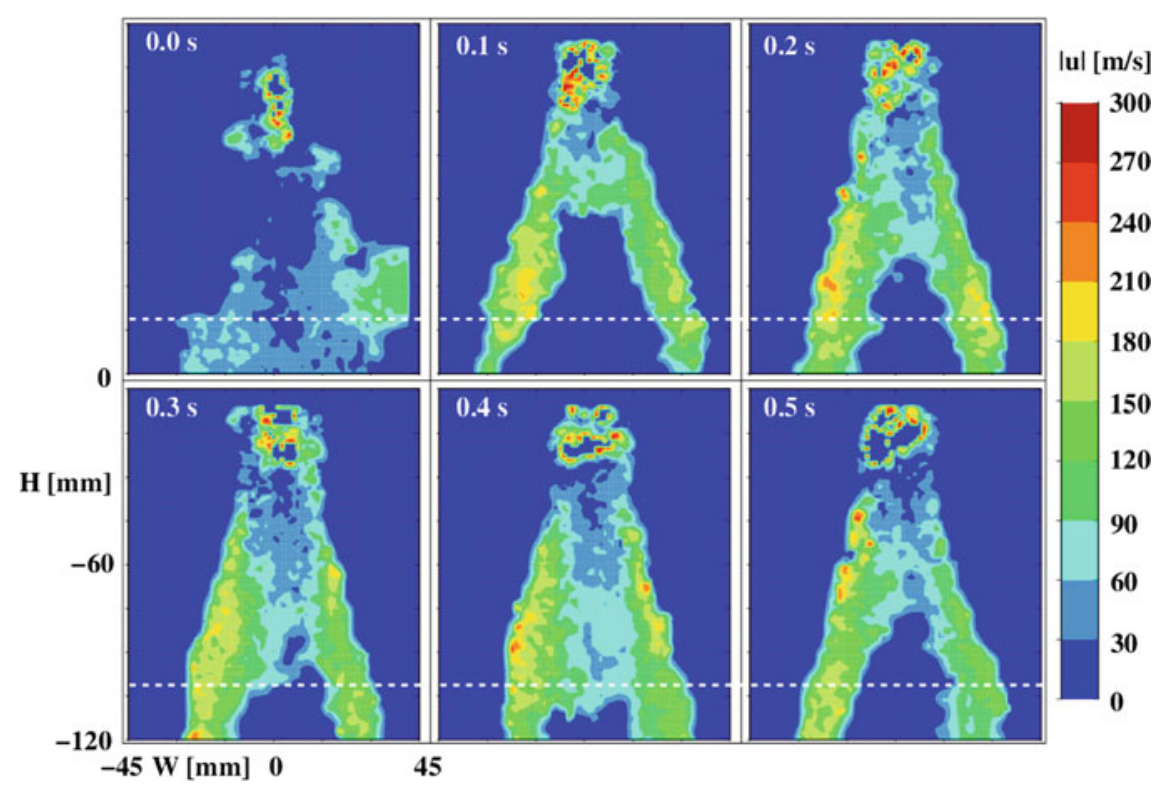

Fig. 3.31 Particle velocities for atomization of X5CrNi18-10 steel [30] 


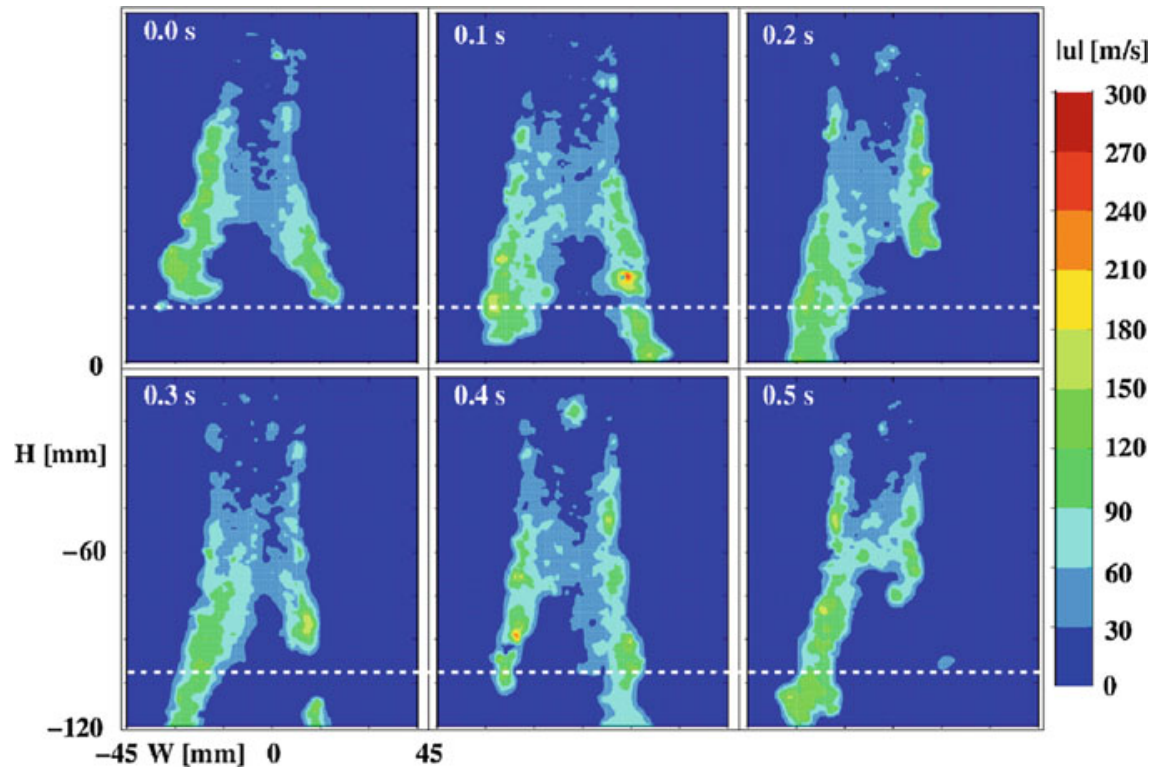

Fig. 3.32 Particle velocities for atomization of X3CrNiMo13-4 steel [30]

\subsubsection{New Geometry and a Set-Up for an Inert Gas Atomization}

Based on the results obtained in the previous chapters it became clear that there are three fundamental problems in the existing inert gas atomization techniques. The first problem is the very thick melt stream coming out of the nozzle. This is necessary to avoid freezing of the nozzle [34]. The result shows that the atomizing inert gas first breaks the stream into larger ligaments and sheets that have to be broken up in further steps downstream of the nozzle. The second problem is extremely low temperature of the gas when it contacts with the melt. The argon has expanded from an initial temperature around or slightly above room temperature to a velocity higher than Mach 1 up to 3 depending on the particular geometry. The result shows that the gas has a temperature around $-50{ }^{\circ} \mathrm{C}$ for Mach 1 and down to $-150{ }^{\circ} \mathrm{C}$ for higher Mach numbers. In principle, the high velocity of the gas is necessary for atomization but when it is that cold, it is counterproductive. This is the reason for the very high superheat of the melt needed for the VIGA set-up (200 K). Finally, the break-up of a thick stream in the centre of the flow with a surrounding gas can be changed. A thin layer of melt on the inner wall of a high-velocity nozzle for the gas is the closest the melt can be exposed to the gas. This is only possible if the gas is hot enough otherwise the nozzle would freeze. This rationale led to the development of a new set-up which has been patented [35]. The idea has been implemented first for the atomization of tin as a proof of principle. Figure 3.33a shows schematically 
(a)

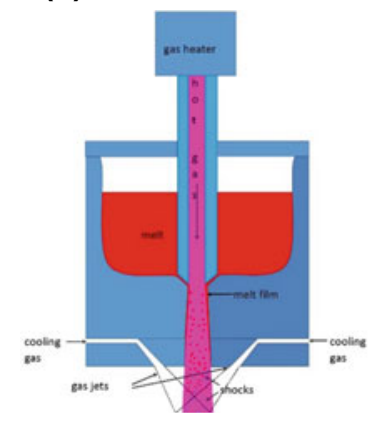

(b)

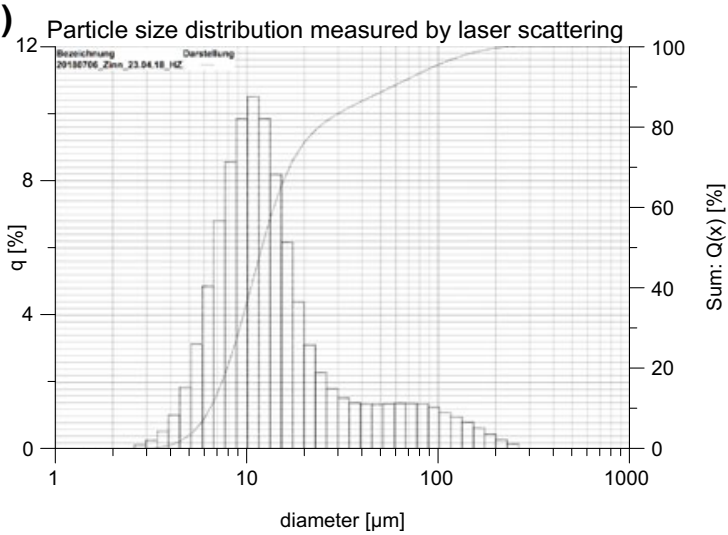

Fig. 3.33 Schematic set-up of the new atomization technique (a) and particle size distribution resulting for the atomization of tin using the new technique $(\mathbf{b})$

the tin atomization set-up. Figure 3.33b shows the resulting particle size distribution measured by laser scattering. The peak of the distribution centers at $10 \mu \mathrm{m}$ for the first experiments. This factor is 2-3 lower than the VIGA results. Of course, the one result is for tin, and the other is for steel. However, when comparing with literature results for tin using similar set-ups as the VIGA the factor 3 is still valid [35].

\subsection{Conclusions}

The present work is focused on the investigations of inert gas atomization and the effects of thermophysical properties of liquid steel alloys' atomization process. Several new research units capable of measuring thermophysical properties of TRIP/TWIP steel melts as well as gas atomization were successfully developed, such as: maximum bubble pressure unit, patented vibrating finger viscometer, density measurement cell based on Archimedean principle, two-colour pyrometer, particleimage-velocimetry unit. The project allowed to gain new data on the surface tension, viscosity and density of the newly developed TRIP/TWIP alloys. Moreover, results regarding the effects of microalloying on the surface tension and viscosity of the steel were obtained. The primary research and practical results of the project development were:

- The surface tension of the TRIP/TWIP steel can be considerably reduced by microalloying with sulphur and selenium;

- reduction of a surface tension reduces the median particle size of the gas-atomized powders;

- The viscosity of the investigated TRIP/TWIP steel can be reduced with phosphorus; 
- The viscosity directly affects the median particle size of the atomized powder;

- Nitrogen alloying does not significantly affect the inert gas atomization process in terms of particle sizes, however, powders phase composition is affected;

- Nitrogen leads to an increase of austenite phase fraction in ready powder particles;

- Temperature of atomization can be an effective measure to affect powder size;

- Measurements delivered data on particles temperature and velocity upon inert-gas atomization.

In general, besides delivering new thermophysical data on liquid alloys and metals, the primary outcome of the research is the confirmation of the successful control of the atomization process by modifying thermophysical properties of the atomized liquid.

Acknowledgements Authors would like to express sincere thanks to the former and current colleagues of the TP A2 and A3 who contributed to development of the CRC 799: Prof. Piotr-Roman Scheller, Dr. Andreas Jahn, Dr. Tobias Dubberstein, Clemens Cirmse, Peter Neuhold, and others. This work was funded by the Deutsche Forschungsgemeinschaft (DFG, German Research Foundation)_Projektnummer: 54473466-SFB 799.

\section{References}

1. K.J. Mysels, Colloids Surf. 43, 241 (1990)

2. K.J. Mysels, Langmuir 2, 428 (1986)

3. T. Dubberstein, M. Hötzel, R. Hagemann, P. Heller, P.R. Scheller, Steel Res. Int. 82, 1122 (2011)

4. T. Dubberstein, P.R. Scheller, in Scientific Reports on Resource Issues (TU Bergakademie Freiberg, Freiberg, 2011), p. 7

5. T. Dubberstein, H.-P. Heller, P.R. Scheller, in Ninth International Conference on "Molten Slags, Fluxes and Salts (Molten12)" (Beijing, China, 2012), p. 10

6. T. Dubberstein, H.-P. Heller, Adv. Eng. Mater. 15, 583 (2013)

7. T. Dubberstein, H.-P. Heller, J. Klostermann, R. Schwarze, J. Brillo, J. Mater. Sci. 50, 7227 (2015)

8. T. Dubberstein, Beiträge zu den thermophysikalischen Eigenschaften flüssiger Metallschmelzen, Ph.D. Thesis, TU Bergakademie Freiberg, 2015

9. K. Ogino, K. Nogi, O. Yamase, ISIJ Int. 23, 234 (1983)

10. B.J. Keene, Int. Mater. Rev. 33, 1 (1988)

11. J. J. Dunkley, in Powder Metal Technologies and Applications (ASM International, 1998), p. 2762

12. J. J. Dunkley, in Advances in Powder Metallurgy (Elsevier, 2013), pp. 3-18

13. T. Dubberstein, H.-P. Heller, Steel Res. Int. 84, 845 (2013)

14. C. Kirmse, H. Chaves, J. Therm. Spray Technol. 24, 690 (2015)

15. Y. Su, Z. Li, K.C. Mills, J. Mater. Sci. 40, 2201 (2005)

16. A. Jahn, K.-P. Steinhoff, T. Dubberstein, P. Franke, M. Weider, S. Wolf, A. Kovalev, A. Glage, A. Weiß, W. Schärfl, K. Eigenfeld, L. Krüger, P.R. Scheller, Steel Res. Int. 85, 477 (2014)

17. T. Dubberstein, M. Schürmann, H.-P. Heller, H. Chaves, DE102014015301 (25 February 2016)

18. T. Dubberstein, H.-P. Heller, O. Fabrichnaya, C.G. Aneziris, O. Volkova, Steel Res. Int. 87, 1024 (2016)

19. T. Dubberstein, M. Schürmann, H. Chaves, H.-P. Heller, C. G. Aneziris, Int. J. Thermophys. 37 (2016) 
20. T. Dubberstein, H.-P. Heller, High Temp.-High Press. 44, 393 (2015)

21. A.A. Romanov, V.V. Kochegarov, Phys. Metalle Und Metallkunde (Физика Металлов И Металловедение) 18, 876 (1964)

22. T. Dubberstein, H.P. Heller, Adv. Mater. Res. 875-877, 1265 (2014)

23. M.J. Assael, K. Kakosimos, R.M. Banish, J. Brillo, I. Egry, R. Brooks, P.N. Quested, K.C. Mills, A. Nagashima, Y. Sato, W.A. Wakeham, J. Phys. Chem. Ref. Data 35, 285 (2006)

24. K.-C. Chou, J.-H. Hu, MTB 22, 27 (1991)

25. I. Korobeinikov, D. Chebykin, X. Yu, S. Seetharaman, O. Volkova, Arch. Mater. Sci. Eng. 92, 28 (2018)

26. M. J. Assael, A. E. Kalyva, K. D. Antoniadis, R. Michael Banish, I. Egry, J. Wu, E. Kaschnitz, W. A. Wakeham, J. Phys. Chem. Ref. Data 39, 033105 (2010)

27. M.J. Assael, A.E. Kalyva, K.D. Antoniadis, R.M. Banish, I. Egry, J. Wu, E. Kaschnitz, W.A. Wakeham, High Temp. High Press. 41, 161 (2012)

28. I. Korobeinikov, A. Perminov, H.-P. Heller, and O. Volkova, Adv. Eng. Mater. (2018)

29. D. M. Goudar, V. C. Srivastava, and G. B. Rudrakshi, EJ 21, 155 (2017)

30. C. Kirmse, H. Chaves, Steel Res. Int. 87, 1295 (2016)

31. R. Gjesing, J. Hattel, U. Fritsching, Eng. Appl. Comput. Fluid Mech. 3, 471 (2009)

32. R. Kaiser, C. Li, S. Yang, D. Lee, Adv. Powder Technol. 29, 623 (2018)

33. N. Zeoli, H. Tabbara, S. Gu, Appl. Phys. A 108, 783 (2012)

34. K. Bauckhage, D. Bergmann, U. Fritsching, H. Lohner, P. Schreckenberg, Chem. Ing. Tech. 10 (2001)

35. H. Chaves, C. Kirmse, H. P. Heller, T. Dubberstein, DE 102015107 876A1 (2016)

Open Access This chapter is licensed under the terms of the Creative Commons Attribution 4.0 International License (http://creativecommons.org/licenses/by/4.0/), which permits use, sharing, adaptation, distribution and reproduction in any medium or format, as long as you give appropriate credit to the original author(s) and the source, provide a link to the Creative Commons license and indicate if changes were made.

The images or other third party material in this chapter are included in the chapter's Creative Commons license, unless indicated otherwise in a credit line to the material. If material is not included in the chapter's Creative Commons license and your intended use is not permitted by statutory regulation or exceeds the permitted use, you will need to obtain permission directly from the copyright holder. 